ARTICLE OPEN

\title{
Oral berberine improves brain dopa/dopamine levels to ameliorate Parkinson's disease by regulating gut microbiota
}

Yan Wang ${ }^{1}$, Qian Tong ${ }^{2}$, Shu-Rong Ma ${ }^{1}$, Zhen-Xiong Zhao ${ }^{1}$, Li-Bin Pan ${ }^{1}$, Lin Cong ${ }^{1}$, Pei Han ${ }^{1}$, Ran Peng ${ }^{1}$, Hang Yu $^{1}$, Yuan Lin ${ }^{1}$, Tian-Le Gao ${ }^{1}$, Jia-Wen Shou ${ }^{1}$, Xiao-Yang Li ${ }^{1}$, Xian-Feng Zhang ${ }^{2}$, Zheng-Wei Zhang ${ }^{1}$, Jie Fu ${ }^{1}$, Bao-Ying Wen ${ }^{1}$, Jin-Bo Yu ${ }^{1}$, Xuetao Cao ${ }^{3}$ and Jian-Dong Jiang (iD)

The phenylalanine-tyrosine-dopa-dopamine pathway provides dopamine to the brain. In this process, tyrosine hydroxylase (TH) is the rate-limiting enzyme that hydroxylates tyrosine and generates levodopa (L-dopa) with tetrahydrobiopterin $\left(\mathrm{BH}_{4}\right)$ as a coenzyme. Here, we show that oral berberine (BBR) might supply $\mathrm{H}^{*}$ through dihydroberberine (reduced BBR produced by bacterial nitroreductase) and promote the production of $\mathrm{BH}_{4}$ from dihydrobiopterin; the increased $\mathrm{BH}_{4}$ enhances $\mathrm{TH}$ activity, which accelerates the production of L-dopa by the gut bacteria. Oral BBR acts in a way similar to vitamins. The L-dopa produced by the intestinal bacteria enters the brain through the circulation and is transformed to dopamine. To verify the gut-brain dialog activated by BBR's effect, Enterococcus faecalis or Enterococcus faecium was transplanted into Parkinson's disease (PD) mice. The bacteria significantly increased brain dopamine and ameliorated PD manifestation in mice; additionally, combination of BBR with bacteria showed better therapeutic effect than that with bacteria alone. Moreover, 2,4,6-trimethyl-pyranylium tetrafluoroborate (TMP-TFB)derivatized matrix-assisted laser desorption mass spectrometry (MALDI-MS) imaging of dopamine identified elevated striatal dopamine levels in mouse brains with oral Enterococcus, and BBR strengthened the imaging intensity of brain dopamine. These results demonstrated that BBR was an agonist of TH in Enterococcus and could lead to the production of L-dopa in the gut. Furthermore, a study of 28 patients with hyperlipidemia confirmed that oral BBR increased blood/fecal L-dopa by the intestinal bacteria. Hence, BBR might improve the brain function by upregulating the biosynthesis of L-dopa in the gut microbiota through a vitamin-like effect.

Signal Transduction and Targeted Therapy (2021)6:77

; https://doi.org/10.1038/s41392-020-00456-5

\section{INTRODUCTION}

The gut microbiota is an increasingly recognized factor that influences brain function, ${ }^{1-6}$ but the mechanism is unknown. Dopamine is a predominant neurotransmitter, and its level in the brain is closely related to the brain function. Dopamine is primarily synthesized in brain neuron cells. ${ }^{7}$ The major synthetic route for dopamine in humans is the "L-phenylalanine (Phe) $\rightarrow$ L-tyrosine $(\mathrm{Tyr}) \rightarrow(\mathrm{s})$-3,4-dihydroxyphenylalanine (levodopa, L-dopa) $\rightarrow$ dopamine (Phe-Tyr-dopa-dopamine)" metabolic pathway. 8 " In this process, the first phase (Phe-Tyr step) is catalyzed by phenylalanine hydroxylase (PAH), and the conversion mainly occurs in liver and kidney. ${ }^{10}$ The liver (or kidney) and/or blood-borne Tyr (from the diet) could cross the blood-brain barrier and enter brain. The Tyr-dopa-dopamine transformation is the second phase and completed in the brain by the enzymes tyrosine hydroxylase (TH) and dopa decarboxylase (DDC). ${ }^{7,11}$ Interruption of this pathway causes neurological diseases, such as phenylketonuria ${ }^{12}$ and Parkinson's disease (PD). ${ }^{7,13}$

$\mathrm{TH}$ is the rate-limiting enzyme for catecholamine biosynthesis which can hydroxylate L-Tyr to L-dopa. TH is a type of monooxygenase containing iron, and it needs tetrahydrobiopterin
$\left(\mathrm{BH}_{4}\right)$ as a cofactor. ${ }^{14}$ When L-dopa is generated, $\mathrm{BH}_{4}$ is transformed into 7,8-dihydrobiopterin $\left(\mathrm{BH}_{2}\right)$, and $\mathrm{BH}_{4}$ is consumed continuously in this process. $\mathrm{BH}_{4}$ can be synthesized in the cytoplasm of cells in two ways: source synthesis and/or remediation. ${ }^{15}$ Under normal conditions, $\mathrm{BH}_{4}$ can be synthesized from the GTP (guanosine triphosphate)- $\mathrm{NH}_{2} \mathrm{P}_{3}$ (D-erythro-7,8-dihydroneopterin triphosphate)- $\mathrm{PPH}_{4}$ (6-pyruvoyltetrahydropterin)- $\mathrm{BH}_{4}$ pathway, which is called "source synthesis"; on the other hand, $\mathrm{BH}_{4}$ can be replenished by means of a remedial pathway of sepiapterin $\rightarrow$ $\mathrm{BH}_{2} \rightarrow \mathrm{BH}_{4}$, and dihydrofolate reductase (DHFR) is the critical enzyme responsible for transforming $\mathrm{BH}_{2}$ to $\mathrm{BH}_{4}{ }^{15}$ Therefore, discovery of an agonist of DHFR might be an effective way to increase $\mathrm{BH}_{4}$ levels and enhance $\mathrm{TH}$ activity.

$\mathrm{BH}_{4}$-producing bacteria have been evidenced in the intestinal flora, ${ }^{16}$ and the Phe-Tyr-dopa-dopamine metabolic pathway exists in microorganisms as well. This suggests that bacteria may contain homologs of the enzyme genes that mammals utilize to create dopamine. ${ }^{17-19}$ In fact, some of the bacteria could be viewed as a biotech factory to produce dopa/dopamine. ${ }^{20}$ Interestingly, bacteria in the human intestine, such as Enterococcus, are producers of dopa/dopamine, ${ }^{21}$ providing a possible

\footnotetext{
${ }^{1}$ State Key Laboratory of Bioactive Substance and Function of Natural Medicines, Institute of Materia Medica, Chinese Academy of Medical Sciences/Peking Union Medical

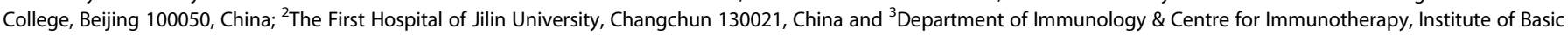
Medical Sciences, Peking Union Medical College, Chinese Academy of Medical Sciences, Beijing 100730, China

Correspondence: Yan Wang (wangyan@imm.ac.cn) or Xuetao Cao (caoxt@immunol.org) or Jian-Dong Jiang (jiang.jdong@163.com)

These authors contributed equally: Yan Wang, Qian Tong, Shu-Rong Ma, Zhen-Xiong Zhao
}

Received: 20 August 2020 Revised: 20 November 2020 Accepted: 9 December 2020

Published online: 24 February 2021 
chemical link between gut and brain. Recent studies have shown that gut microbiota could modulate brain function through microbial-derived metabolites, such as serotonin. ${ }^{22}$ So, the key question becomes how could we modulate brain function in a practical way.

Berberine (BBR) is a natural compound (Supplementary Fig. S1a, mw 371.8) isolated from herbs, such as Coptis chinensis and Berberis vulgaris. BBR has been used for decades in China as an over-the-counter (OTC) drug to treat patients with diarrhea. Since 2004, we and others have identified BBR as a safe and efficient medicine for hyperlipidemia and type 2 diabetes with novel mechanisms. ${ }^{23}$ Clinical efficacy of BBR in lowering lipids and glucose has been widely confirmed in the past decade. ${ }^{23-26}$ Furthermore, BBR has been repeatedly reported, from independent groups, to have beneficial effects on brain function. ${ }^{27,28}$ Among the groups, two Korean laboratories investigated the antiPD effect of BBR in animals. One group found BBR effective in treating PD in mice, ${ }^{29}$ but the other obtained negative results in rats. ${ }^{30}$ In analysis of the difference, we found that the first group gave BBR to mice orally, whereas the second group treated rats with BBR intraperitoneally (i.p.). Thus, we assumed that the gut microbiota might be the answer. In addition, BBR administered through oral route is poorly absorbed in the intestine, ${ }^{31-33}$ and its concentration in intestine is high. This provoked our curiosity to explore the interaction between BBR and the gut flora, as well as the chemical mechanism of BBR that links the gut microbiota with the central nervous system (CNS). The main neurotransmitters, such as L-dopa, have become the research target in this study. We found that oral administration of BBR enhanced $\mathrm{TH}$ activity to produce L-dopa by triggering the biosynthesis of $\mathrm{BH}_{4}$ in the gut microbiota, elevated blood, and brain dopa/dopamine concentrations, and eventually improved physical performance in animals. Detection of the pathway intermediates in clinical subjects verified the effect of BBR in humans. The results might shed new light on the control of the crosstalk between gut and brain.

\section{RESULTS}

BBR increased dopa/dopamine production in the gut microbiota in vivo

L-Dopa is a first-line drug to treat PD, as it could cross the blood-brain barrier and then through the action of DDC be converted into dopamine, which there is a shortage in PD. ${ }^{34}$ Dopa and dopamine (dopa/dopamine) are low-molecular-weight compounds that could be detected in biological samples quantitatively and qualitatively, using liquid chromatography with tandem mass spectrometry (LC-MS/MS; Supplementary Fig. S1b, c). In the present study, we show that oral administration of BBR (100, $200 \mathrm{mg} / \mathrm{kg}$ ) in mice significantly increased dopa/dopamine production of the intestinal bacteria in $6 \mathrm{~h}$ (Fig. 1a). The intestinal dopa/dopamine then entered the blood and brain (dopa only), showing an increased dopa/dopamine in both the blood and brain, in a dose- and time-dependent manner (Fig. 1b, c). The significance of difference seen in dopamine was, in general, larger than that for dopa at the study time points (Fig. 1a), because dopa is unstable and simply converted into dopamine in the presence of tissue DDC. ${ }^{35}$

To verify the role of the gut microbiota in the BBR-induced increase in dopa/ dopamine, pseudo-germ-free (PGF) ICR mice were used with a previously described method. ${ }^{33}$ The mice were pretreated or untreated with oral antibiotics for 3 days, followed by administration of BBR orally with or without concurrent treatment with antibiotics. The intestinal bacterial colony number in the mice treated with antibiotics was significantly lower than that of the mice untreated with antibiotics $(-73 \%$, Supplementary Fig. S2a). The increase in dopa/dopamine in feces, blood, and brain was abolished in the BBR-treated mice receiving antibiotics, at all study time points
(Supplementary Fig. S2b-d). It appeared that oral antibiotics largely reduced the size of gut flora, and thus decreased their capacity to produce dopa/dopamine in the intestine.

Furthermore, to learn the direct action of BBR in conditions free of intestinal bacteria, ICR mice were treated with BBR via i.p. injection. BBR at $20 \mathrm{mg} / \mathrm{kg}$ was used in the i.p. injection experiment, considering that the bioavailability of BBR is much $<5 \%{ }^{31,32}$ As shown in Fig. 1d, treating mice with BBR $(20 \mathrm{mg} / \mathrm{kg}$, i. p.) caused no change in the level of dopa/dopamine in feces, blood, and brain, suggesting gut microbiota essential for the BBRinduced increase in dopa/dopamine in the body.

In addition, isotope $\left({ }^{15} \mathrm{~N}\right)$-labeled tyrosine $\left({ }^{15} \mathrm{~N}\right.$-Tyr) was used to validate that the increased brain dopamine by BBR was originated from the intestine. The ${ }^{15} \mathrm{~N}$-dopamine and dopamine were identified through comparison of their quantitative ion pair using LC-MS/MS 8050, in which $155.20 \rightarrow 137.05(\mathrm{~m} / \mathrm{z})$ was for ${ }^{15} \mathrm{~N}$ dopamine and $154.20 \rightarrow 137.05(\mathrm{~m} / \mathrm{z})$ was for dopamine. As shown in Fig. 1e, ${ }^{15} \mathrm{~N}$-dopamine was detected well in mouse brain, suggesting that the brain ${ }^{15} \mathrm{~N}$-dopamine could be from the intestine. Multistage mass spectrometry (LC instrument coupled to an ion trap time-of-flight mass spectrometer, LC/MS ${ }^{n}$-IT-TOF) was also used to recognize ${ }^{15} \mathrm{~N}$-dopamine and dopamine in brain (Supplementary Fig. S2e). Using dopamine as a reference, ${ }^{15} \mathrm{~N}$ dopamine generated a $[\mathrm{M}+\mathrm{H}]^{+}$peak at $\mathrm{m} / \mathrm{z}$ 155.0861, 1 Da more than dopamine in peak $\mathrm{MS}^{1}$; the value of $137.0566(\mathrm{~m} / \mathrm{z})$ in peak $\mathrm{MS}^{2}$ demonstrated a deamination structure, calculated as that of dopamine. The fragments of $119.0476(\mathrm{~m} / \mathrm{z})$ and $91.0499(\mathrm{~m} / \mathrm{z})$ from $\mathrm{MS}^{3}$ showed values very close to those of dopamine $(119.0477(\mathrm{~m} / \mathrm{z})$ and $91.0499(\mathrm{~m} / \mathrm{z}))$. The results indicated that dopamine and ${ }^{15} \mathrm{~N}$-dopamine could be clearly identified and analyzed quantitatively by LC-MS/MS (Supplementary Fig. S2e). Figure $1 \mathrm{f}$ shows that intestinal ${ }^{15} \mathrm{~N}$-Tyr was the raw material for the synthesis of ${ }^{15} \mathrm{~N}$-dopamine in brain, and oral administration of BBR significantly increased brain ${ }^{15} \mathrm{~N}$-dopamine $\left(42 \%\right.$, $\left.{ }^{* *} P<0.001\right)$. Pretreating the mice with antibiotics for 3 days (oral, see the "Methods" section) decreased the effect of BBR on ${ }^{15} \mathrm{~N}$-dopamine production. The results suggest that the gut microbiota could be a supply for brain dopamine in vivo. Oral antibiotics without BBR treatment has been tested as controls. The result showed that ${ }^{15} \mathrm{~N}-$ dopamine in brain decreased by $-17.2 \%$ in the antibiotics treatment group (Supplementary Fig. S2f).

To further verify this hypothesis, blood, liver homogenate, brain homogenate, or gut flora of the ICR mice was incubated with ${ }^{15} \mathrm{~N}$ Tyr in vitro, respectively, followed by detection of ${ }^{15} \mathrm{~N}$-dopamine generated in the four systems above. The results showed that ${ }^{15} \mathrm{~N}$ dopamine was detected in the brain homogenate and gut bacteria (Fig. S2g-j), but not in the blood and liver homogenate, suggesting brain and intestinal bacteria the main sites of dopamine biosynthesis in vivo as they contain both $\mathrm{TH}$ and DDC. Furthermore, when treating the brain homogenate or gut bacteria with BBR, the ${ }^{15} \mathrm{~N}$-dopamine increased in gut bacteria, but not in the brain because brain tissue does not have dihydroberberine (dhBBR; see content below). It appears that the increased brain dopamine by BBR was from dopa in the gut microbiota, which could be viewed as another "organ" of dopa/dopamine production, in addition to the brain.

BBR stimulated intestinal bacteria to produce dopa/dopamine in vitro

The experiments were then extended to the in vitro test. Treating intestinal bacteria, as a whole, with BBR (10 and $20 \mu \mathrm{g} / \mathrm{mL})$ for $24 \mathrm{~h}$ in vitro increased their production of dopa/dopamine (Fig. 2a). Then, we detected the effect of BBR on ten intestinal bacterial strains. As shown in Fig. 2b, out of the ten strains, four bacterial strains ( $E$. faecalis, E. faecium, Proteus mirabilis, and Lactobacillus acidophilus) showed a significant increase in dopa after BBR treatment ( 10 and $20 \mu \mathrm{g} / \mathrm{mL}$ for $12 \mathrm{~h}$ ), three had almost no change in dopa production, and another three strains had dopa 

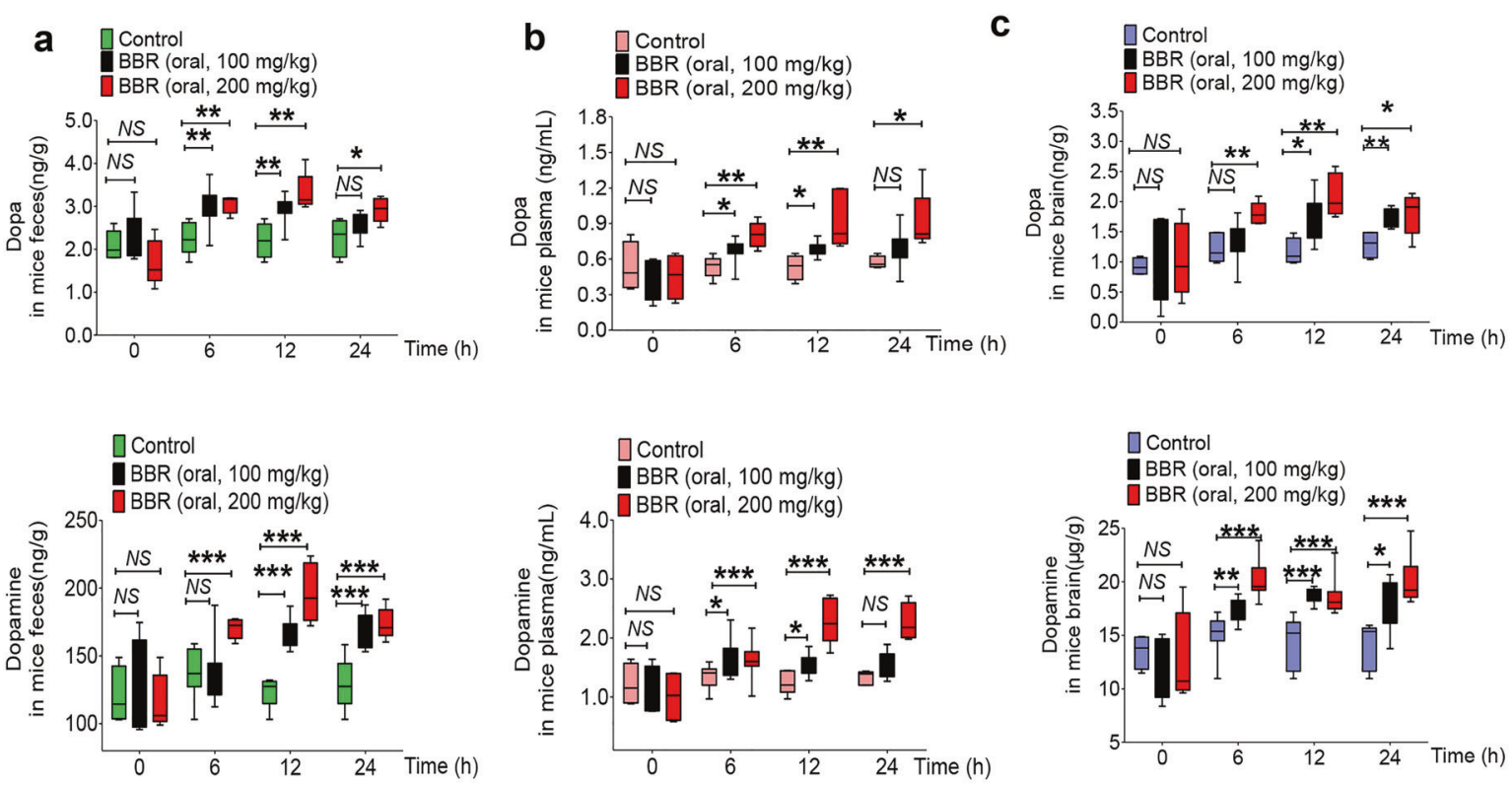

d
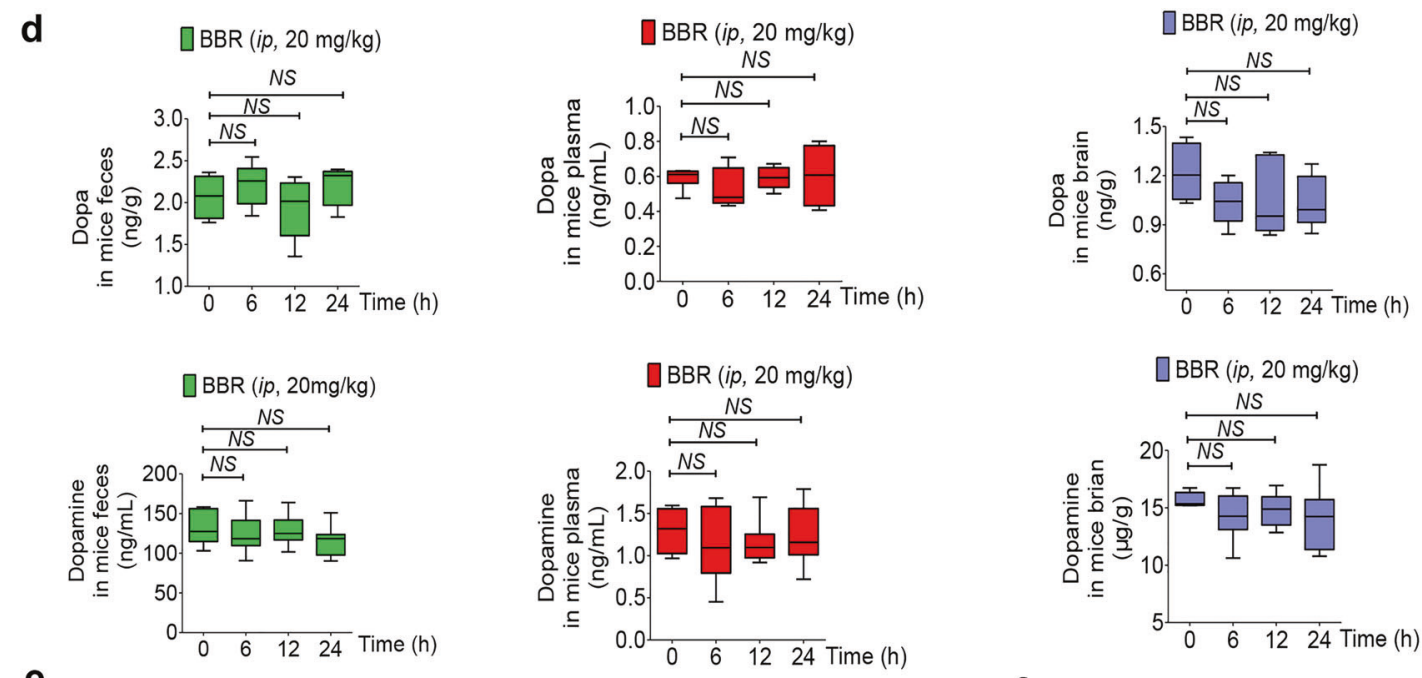

$(\mathrm{x} 10,000)$
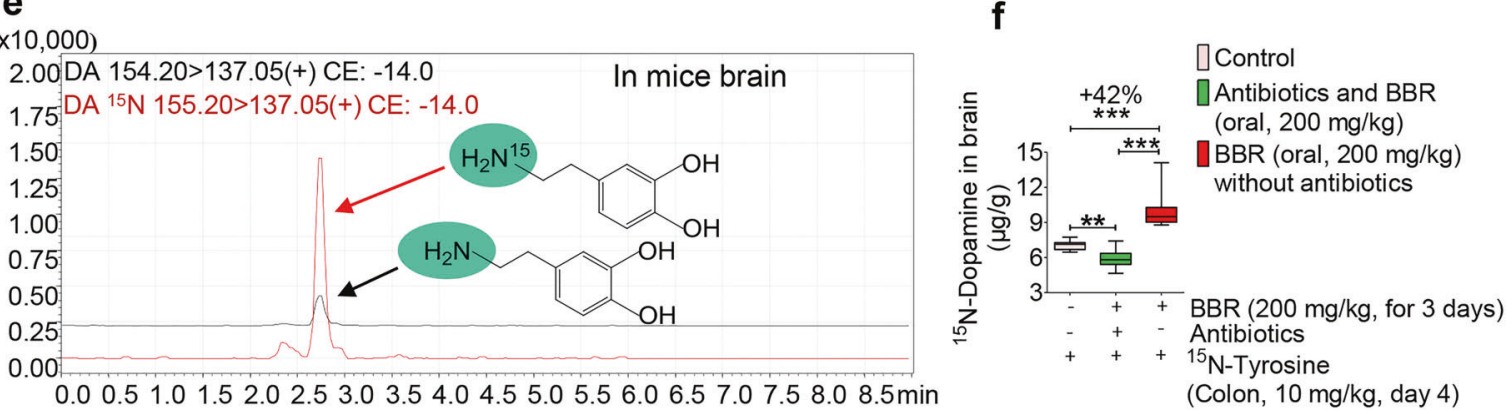

Fig. 1 BBR increased dopa/dopamine production in the gut microbiota in vivo. a Dopa/dopamine significantly increased in the feces of ICR mice at $0,6,12$, and $24 \mathrm{~h}$ after oral administration of BBR $\left(100\right.$ and $200 \mathrm{mg} / \mathrm{kg}$, respectively; mean \pm SD, $* P<0.05, * * P<0.01$ for dopa and ${ }^{* * *} P$ $<0.001$ for dopamine). b Dopa/dopamine showed a dose- and time-dependent increase in plasma after BBR treatment (mean \pm SD, ${ }^{*} P<0.05$ and ${ }^{* *} P<0.01$ for dopa; ${ }^{*} P<0.05$, ${ }^{* * *} P<0.001$ for dopamine). c Dopa/dopamine showed a similar dose- and time-dependent increase in the brain after BBR treatment (mean \pm SD, ${ }^{*} P<0.05$ and ${ }^{*} P<0.01$ for dopa; ${ }^{*} P<0.05,{ }^{*} P<0.01$, and ${ }^{* * *} P<0.001$ for dopamine). d Intraperitoneal injection (i.p.) of BBR into the ICR mice did not increase the levels of dopa/dopamine in the feces, plasma, and brain at any of the study time points, which was different from the results of BBR in oral administration (mean \pm SD, NS no significance). e Mass spectra of ${ }^{15} \mathrm{~N}$-dopamine and dopamine in mouse brains. $f$ Intestinal ${ }^{15} \mathrm{~N}$-Tyr was the raw material for the synthesis of ${ }^{15} \mathrm{~N}$-dopamine in brain. Pretreating the mice with antibiotics for 3 days attenuated the effect of BBR on ${ }^{15} \mathrm{~N}$-dopamine production (mean $\pm \mathrm{SD},{ }^{* *} P<0.01,{ }^{* * * P} P 0.001$ ), and oral administration of BBR significantly increased ${ }^{15} \mathrm{~N}$-dopamine in the brain $\left({ }^{*} P<0.05\right)$ 
a

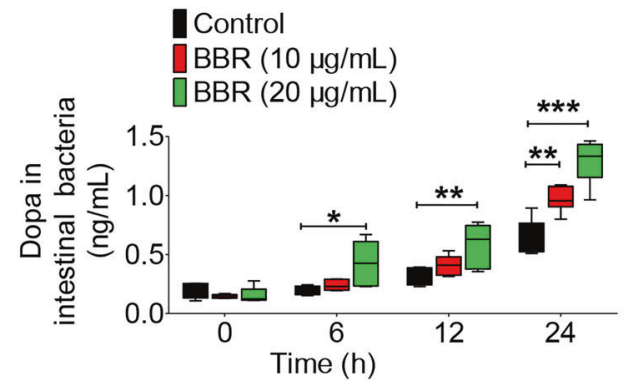

b

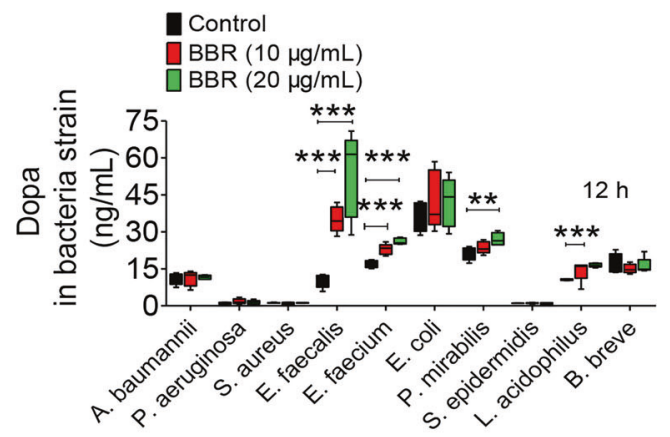

C

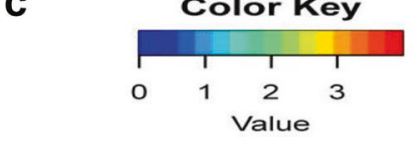

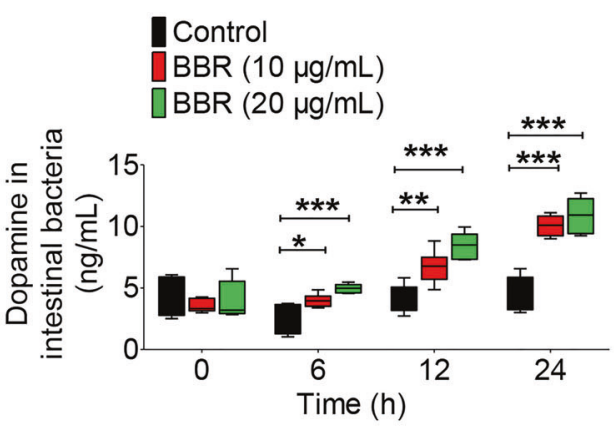

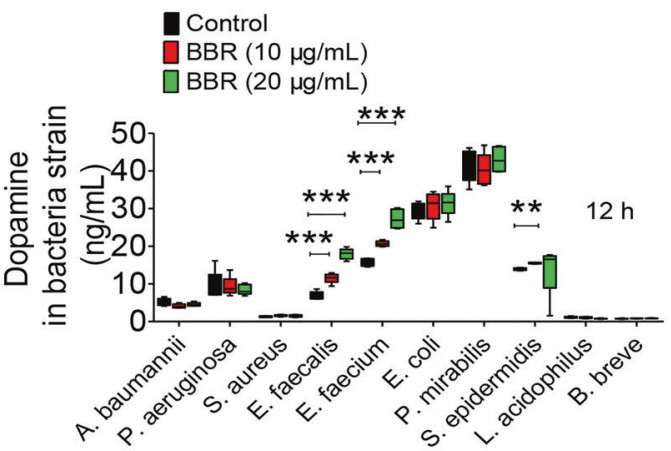

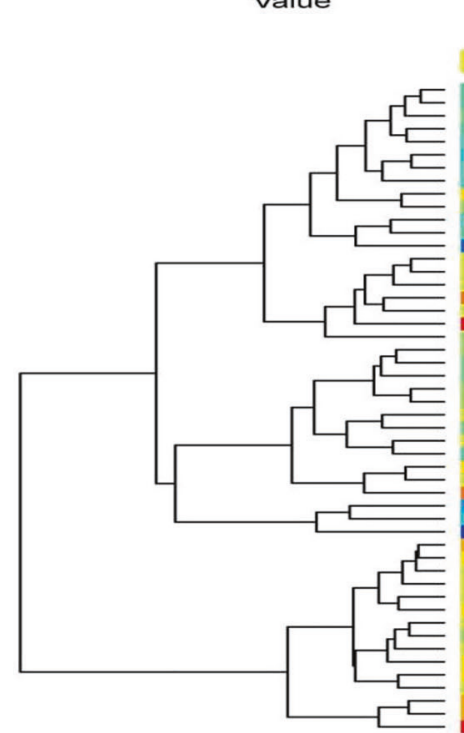
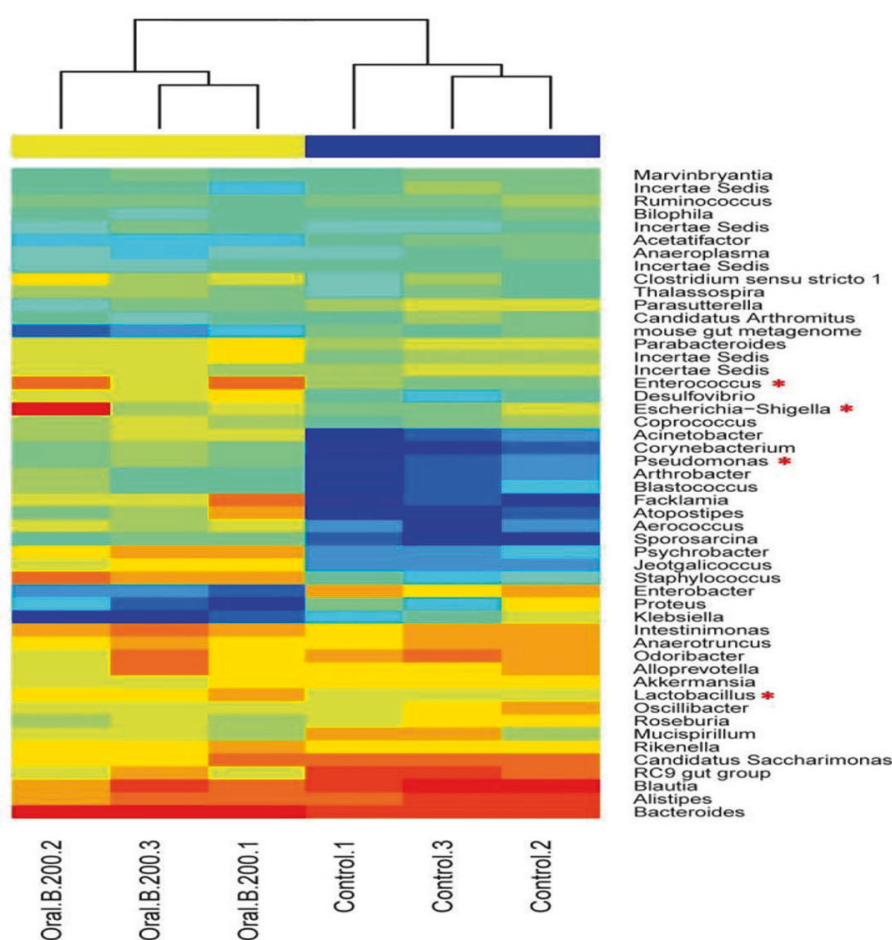

Fig. 2 BBR stimulated intestinal bacteria to produce dopa/dopamine. a Levels of dopa/dopamine increased significantly at $0,6,12$, and $24 \mathrm{~h}$ after BBR treatment $\left(10\right.$ and $20 \mu \mathrm{g} / \mathrm{mL}$, respectively) in the intestinal bacteria of SD rats in vitro (mean \pm SD, ${ }^{*} P<0.05,{ }^{* *} P<0.01$, and ${ }^{* * *} P<$ 0.001 , for dopa and dopamine). b Effect of BBR $(10 \mu \mathrm{g} / \mathrm{mL})$ in ten intestinal bacterial strains in vitro. Out of the ten strains, four bacterial strains (E. faecalis, E. faecium, P. mirabilis, and L. acidophilus) showed a significant increase in dopa after BBR treatment $(10 \mathrm{and} 20 \mu \mathrm{g} / \mathrm{mL}$ for $12 \mathrm{~h})$, six had almost no change in dopa production. Of note, the increase in dopa by E. faecalis and E. faecium showed a dose-dependent manner with BBR. The BBR-induced dopamine production profile in the ten strains was different from that of dopa, that is, three bacterial strains (E. faecalis, E. faecium, and S. epidermidis) showed a significant increase in dopamine after BBR treatment $(10 \mu \mathrm{g} / \mathrm{mL}$ for $12 \mathrm{~h})$, seven had almost no change on dopamine production. Of note, the increase in dopamine by E. faecalis and E. faecium showed a similar dose-dependent manner with BBR. c Changes in the intestinal bacterial composition as a result of BBR treatment. The heat map of the top 50 bacterial genera exhibited the most substantial change in abundance after exposure to BBR; the proportion of dopa/dopamine-producing bacteria increased, including Enterococcus, Escherichia-Shigella, Pseudomonas, and Lactobacillus (labeled with the red "*") 
concentrations under the detection level, with or without BBR treatment (not detectable, ND). The dopamine profile by BBR in the ten strains was different from that of dopa, three bacterial strains (E. faecalis, E. faecium, and Staphylococcus epidermidis) showed a significant increase in dopamine after BBR treatment $(10 \mu \mathrm{g} / \mathrm{mL}$ for $12 \mathrm{~h})$, four had almost no change in dopamine production, and another three strains had a dopamine concentration that was ND, with or without BBR treatment. Although there were several strains producing both L-dopa and dopamine, based on their dopa production, we selected $E$. faecalis and $E$. faecium for further investigation. As shown in Supplementary Fig. S3a, b, dopa in both bacterial strains increased 6 and $12 \mathrm{~h}$ after BBR treatment $\left(10 \mu \mathrm{g} / \mathrm{mL},{ }^{*} P<0.05,{ }^{* *} P<0.01\right)$, but the increase vanished at $24 \mathrm{~h}$ for $E$. faecalis, probably due to the conversion from dopa to dopamine. Meanwhile, the production of dopamine in these two strains significantly increased over time $\left({ }^{*} P<0.05,{ }^{*} P<0.01\right.$, and ${ }^{* * *} P<0.001$ for 6,12 , and $24 \mathrm{~h}$ time points). $P$. mirabilis or Escherichia coli was not responsive to BBR at all (Supplementary Fig. S3c, d). On the other hand, incubating the tissue homogenate of mouse brain, intestine, or liver, with BBR did not increase the dopa/dopamine levels (Supplementary Fig. S3e-g). The results supported that the gut microbiota is the main target of BBR for dopa/dopamine production in the body.

In addition, changes in the intestinal bacterial composition were detected as well. The ICR mice were treated orally with BBR $(200 \mathrm{mg} / \mathrm{kg})$ for $24 \mathrm{~h}$ and their fecal samples were taken for bacterial composition analysis. The barcode pyrosequencing of the V3/V4 regions of the $16 \mathrm{~S}$ rRNA gene revealed an augmentation of the dopa/dopamine-producing intestinal bacteria in mice treated with BBR. Figure 2c shows the heat map of the top 50 bacterial genera that exhibited the most substantial change in abundance after exposure to BBR. Of the 50 genera, 18 had their abundance increased after BBR treatment, of which 4 genera were documented to be dopa/dopamine producers, including Enterococcus, $^{21}$ Escherichia-Shigella, ${ }^{36}$ Pseudomonas, $^{37}$ and Lactobacil$\operatorname{lus}^{38}$ (Fig. 2c). The increase in the abundance of dopa/dopamineproducing bacteria by BBR might represent a favored selection of $B B R$ in the gut bacterial community. Thus, BBR appeared to elevate dopa/dopamine levels in the gut microbiota by either stimulating dopa/dopamine biosynthesis in bacteria or increasing the abundance of dopa/dopamine-producing bacteria.

BBR activated dopa/dopamine biosynthesis in gut microbiota and improved brain function in animals

TH and DDC are two key enzymes that respectively convert tyrosine to dopa and then dopa to dopamine. ${ }^{39}$ We first determined the activity of TH and level of DDC after exposing the bacteria to BBR for $12 \mathrm{~h}$. Enzyme assays showed that BBR $(10 \mu \mathrm{g} / \mathrm{mL})$ treatment in vitro increased the TH activity in intestinal flora by $23 \%$ and DDC level by $28 \%$ (Fig. $3 a,{ }^{*} P<0.05,{ }^{*} P<0.01$ ). Meanwhile, we first measured the influence of BLMA5 and benserazide on enzyme activity or level of TH and DDC. The results showed that the activity of $\mathrm{TH}$ or level of DDC was significantly inhibited by TH or DDC inhibitors respectively $\left({ }^{*} P<\right.$ 0.01 for $\mathrm{TH} ;{ }^{*} P<0.05$ for DDC, Supplementary Fig. S3h). As the coenzyme of $\mathrm{TH}$, the $\mathrm{BH}_{4}$ level was enhanced in the intestinal bacteria after the treatment with $\mathrm{BBR}$ or its intestinal metabolite dhBBR at 6 and $12 \mathrm{~h}$ (Fig. $3 \mathrm{~b},+23 \% \uparrow,+31 \% \uparrow$ for BBR at $20 \mu \mathrm{g} / \mathrm{mL}$, ${ }^{* *} P<0.01,{ }^{* * *} P<0.001 ;+26 \% \uparrow,+34 \% \uparrow$ for dhBBR at $20 \mu \mathrm{g} / \mathrm{mL}$, ${ }^{*} P<0.01$ ), with the chemical mechanism illustrated below. In addition, the DDC coenzyme vitamin $\mathrm{B} 6\left(\mathrm{VB}_{6}\right)$ level was enhanced in the intestinal bacteria at $12 \mathrm{~h}$ (Fig. $3 \mathrm{~b},+16 \% \uparrow$ for a BBR dose of $20 \mu \mathrm{g} / \mathrm{mL},{ }^{* * *} P<0.001 ;+19 \% \uparrow$ for a dhBBR dose of $20 \mu \mathrm{g} / \mathrm{mL}$, ${ }^{* *} P$ $<0.01)$. We consider it might be the main mechanism by which BBR promotes dopa/dopamine production in bacteria. If true, inhibition of the two enzymes might suppress BBR-induced dopa/ dopamine production in the gut microbiota. First, we showed that TH inhibitor bleomycin A5 (BLMA5) or DDC inhibitor benserazide did not change the abundance of the intestinal bacteria in the range of $0-100 \mu \mathrm{M}$ (Fig. 3a). Next, as shown in Fig. 3c, the addition of TH inhibitor BLMA largely reduced BBR's effect $(10$ or $20 \mu \mathrm{g} / \mathrm{mL}$, for 6 or $12 \mathrm{~h}$ ) on dopa production in the gut microbiota $\left({ }^{* *} P<\right.$ 0.01 ), and the addition of DDC inhibitor benserazide (Fig. 3c) reduced the BBR-induced production of dopamine $(* * * P<0.001)$. In addition, we treated the gut microbiota with BBR $(10$ or $20 \mu \mathrm{g} /$ $\mathrm{mL}$ for 6 or $12 \mathrm{~h}$ ) in combination with benserazide. As shown in Fig. 3d, combination of BBR with benserazide further increased the dopa level in the gut microbiota, most likely because the conversion from dopa to dopamine was blocked, while dopa biosynthesis was increased by BBR. The results revealed a stimulatory activity of BBR on dopa/dopamine biosynthesis, working through activation of both $\mathrm{TH}$ and $\mathrm{DDC}$ in the gut microbiota. As intestinal dopamine could not cross the blood-brain barrier, our focus was on dopa. Combination of BBR with DDC inhibitors should further increase dopa in blood and therefore the level of dopamine in brain.

Although TH and DDC are present in the brain, coincubation of brain homogenate with BBR did not increase the brain levels of dopa/dopamine (Fig. 3e). However, coincubation of brain homogenate with dhBBR, a BBR metabolite produced by nitroreductase in gut flora, significantly increased the dopa/dopamine in the brain (Fig. 3e, ${ }^{* *} P<0.01,{ }^{* * *} P<0.001$; Fig. 3f, ${ }^{*} P<0.05$ ). Accordingly, we found that the activity of $\mathrm{TH}$ (and the coenzyme $\mathrm{BH}_{4}$ ) and the level of DDC (and the coenzyme $\mathrm{VB}_{6}$ ) in brain was elevated by dhBBR (Fig. 3g, h). Thus, BBR-induced increase in dopa/dopamine production in the gut microbiota might be mediated through its intestinal metabolite dhBBR, which could activate $\mathrm{TH}$ and $\mathrm{DDC}$ by elevating $\mathrm{BH}_{4}$ and $\mathrm{VB}_{6}$ levels, respectively. The putative chemical mechanism of dhBBR on TH activity is shown in Fig. 4.

DhBBR exhibited excellent docking performance in docking onto $\mathrm{TH}$ (pdb: $2 \mathrm{TOH}$ ) with a binding free energy of $-44.26 \mathrm{kcal} /$ mol. DhBBR anchored into the binding site of TH through multiple interactions with its scaffold and the side chains (Fig. 4). This binding pocket is also the one for $\mathrm{BH}_{2}$. The distance between the 7-N atom of the $\mathrm{N}-\mathrm{C}$ group in $\mathrm{dhBBR}$ and the $\mathrm{C}_{4}$ atom of the $\mathrm{N}_{3}=\mathrm{C}_{4}$ bond of $\mathrm{BH}_{2}$ was $\sim 9.395 \AA$, which is within the optimal distance for electron transfer. When dhBBR approached $\mathrm{BH}_{2}$ in the pocket, $\mathrm{BH}_{2}$ obtained $\mathrm{H}^{\circ}$ from the dhBBR-BBR system, and its reduction was activated in which $\mathrm{H}^{\circ}$ from dhBBR $\left(\mathrm{N}_{7}-\mathrm{C}_{8}\right)$ moved to the $\mathrm{N}_{3}=\mathrm{C}_{4}$ bond in $\mathrm{BH}_{2}$, and $\mathrm{N}_{3}=\mathrm{C}_{4}$ was then transformed into $\mathrm{N}_{3}-\mathrm{C}_{4}\left(\mathrm{BH}_{2}\right.$ was converted into $\left.\mathrm{BH}_{4}\right)$. In the meanwhile, dhBBR lost $\mathrm{H}^{\circ}$ and was oxidized into BBR (Fig. 4). The increased $\mathrm{BH}_{4}$ in intestinal bacteria accelerated the transformation from tyrosine to L-dopa in the presence of reactive oxygen species (ROS; $\mathrm{H}_{2} \mathrm{O}_{2}$, etc.), as well as $\mathrm{Fe}^{2+}$. Accordingly, $\mathrm{BH}_{4}$ is converted into tetrahydrobiopterin-4a-carbinolamine. The chemical mechanism is shown in Fig. 4. ${ }^{33,40-42}$ To verify that dhBBR activates the TH enzyme by promoting $\mathrm{BH}_{4}$, we added dhBBR to the mixture of $\mathrm{BH}_{2}$ (as substrate) and DHFR at $37^{\circ} \mathrm{C}$ for $2 \mathrm{~h}$. The results showed that $\mathrm{BH}_{2}$ decreased significantly $\left({ }^{*} P<0.05\right)$ accompanied by increasing $\mathrm{BH}_{4}\left({ }^{*} P<0.05\right.$; Fig. $\left.3 \mathrm{i}\right)$, suggesting that dhBBR might promote biotransformation from $\mathrm{BH}_{2}$ to $\mathrm{BH}_{4}$ in the bioactivity of DHFR. Besides, when the inhibitor of DHFR (methotrexate, $100 \mu \mathrm{M})$ was added, the production of dopa/dopamine was significantly inhibited $(* * P<0.01$ for dopa; $P=0.0556$ for dopamine, shown in Fig. 3j). It appeared that dhBBR is an agonist of DHFR possessing a similar function to that of the coenzyme NADPH.

Since brain tissue is free of nitroreductase and does not have $\mathrm{dhBBR}^{33}$ the dopa/dopamine production in the brain tissue treated with BBR remains unchanged. ${ }^{33}$ In fact, the in vivo experiments showed that dhBBR was detectable in the intestine only, but not in the blood and brain, ${ }^{33}$ strongly supporting the assumption that the increased dopamine in the brain by BBR was from the gut microbiota. 
b

$\square$ Control BBR(10 $\mathrm{gg} / \mathrm{mL}) \square \mathrm{dhBBR}(10 \mathrm{\mu g} / \mathrm{mL})$
$\operatorname{BBR}(20 \mathrm{\mu g} / \mathrm{mL}) \square \mathrm{dhBBR}(20 \mathrm{\mu g} / \mathrm{mL})$ $* *(+34 \%)$ a

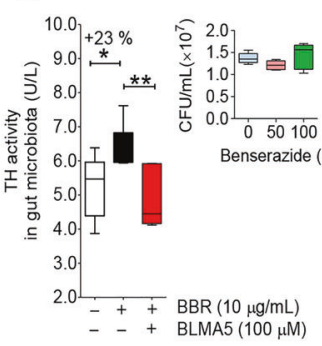

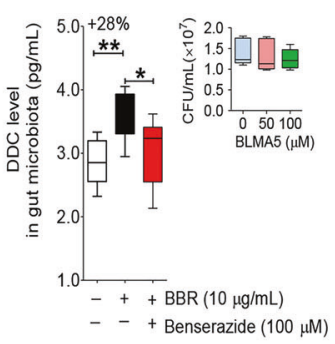

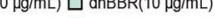

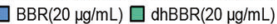

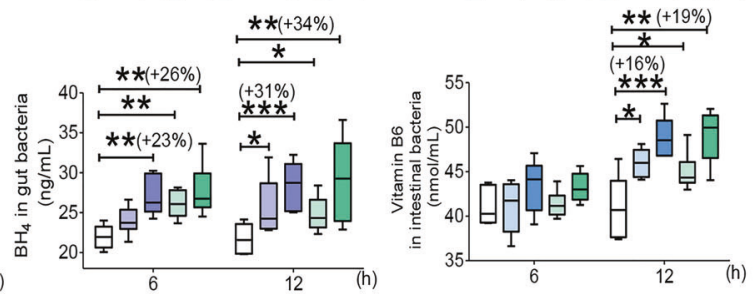

C

$\square$ Control

BBR $(10 \mu \mathrm{g} / \mathrm{mL})$

$\square \operatorname{BBR}(10 \mu \mathrm{g} / \mathrm{mL})$ and BLMA5 (100 $\mu \mathrm{M})$

BBR $(10 \mu \mathrm{g} / \mathrm{mL})$
$\mathrm{BBR}(20 \mathrm{~g} / \mathrm{L})$

BBR $(20 \mu \mathrm{g} / \mathrm{mL})$ and BLMA5 $(100 \mu \mathrm{M})$

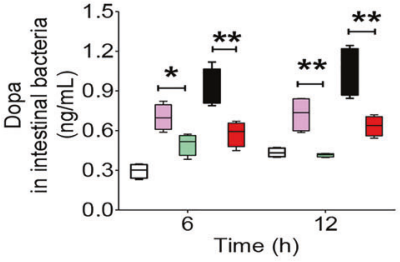

e

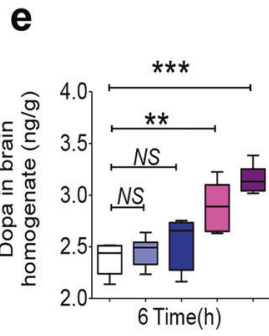

Control BBR( $(10 \mu \mathrm{g} / \mathrm{mL})$ DBBR(20 $\mu \mathrm{g} / \mathrm{mL})$ DhBBR(10 $\mu \mathrm{g} / \mathrm{mL})$

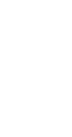

$\square$ Control

पBBR $(10 \mu \mathrm{g} / \mathrm{mL})$

DBBR $(10 \mu \mathrm{g} / \mathrm{mL})$ and Benserazide $(100 \mu \mathrm{M})$

BBR $(20 \mu \mathrm{g} / \mathrm{mL})$

BBR $(20 \mu \mathrm{g} / \mathrm{mL})$ and Benserazide $(100 \mu \mathrm{M})$

d

Control

BBR $(10 \mu \mathrm{g} / \mathrm{mL})$

BBR $(10 \mu / \mathrm{mL})$ and Benserazide $(100 \mu \mathrm{M})$ BBR $(20 \mu \mathrm{g} / \mathrm{mL})$

BBR $(20 \mu \mathrm{g} / \mathrm{mL})$ and Benserazide $(100 \mu \mathrm{M})$
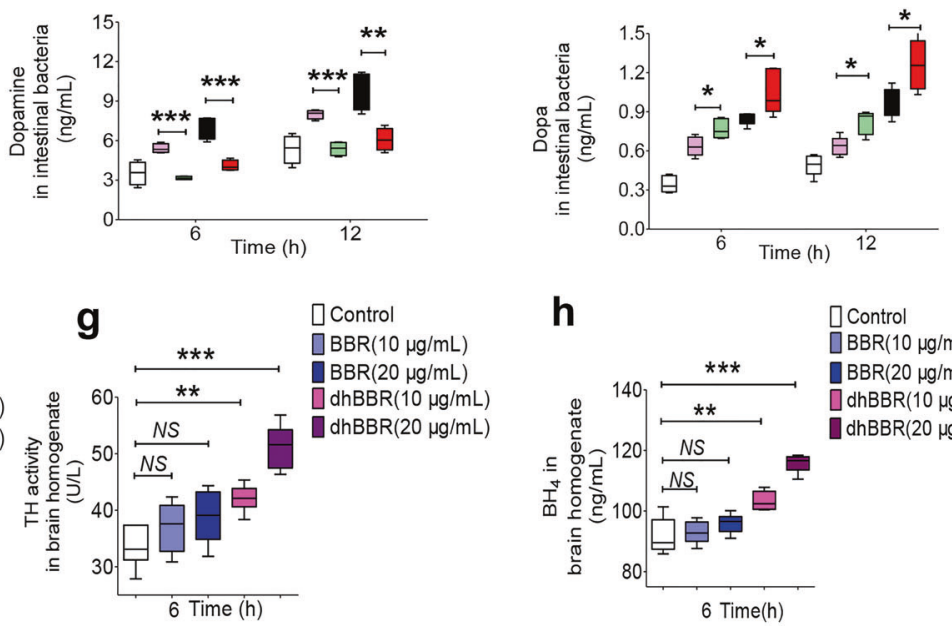

h

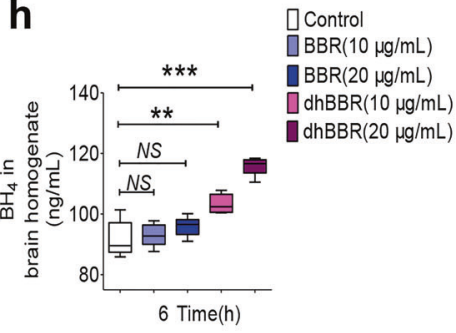

6 Time(h)

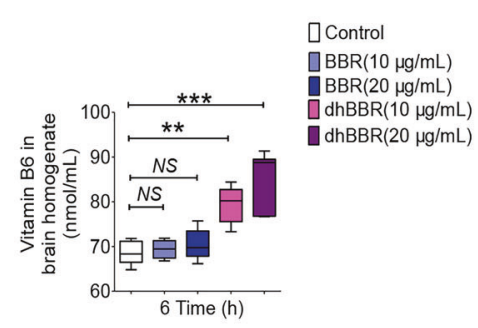

f

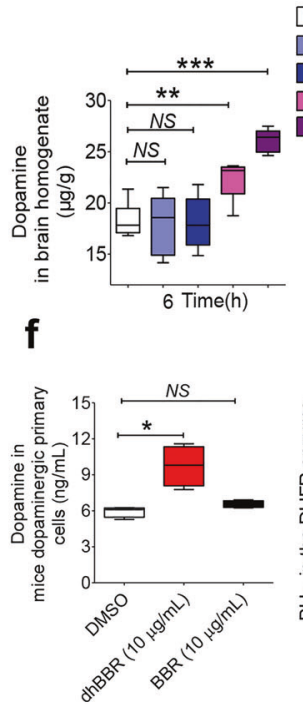

i
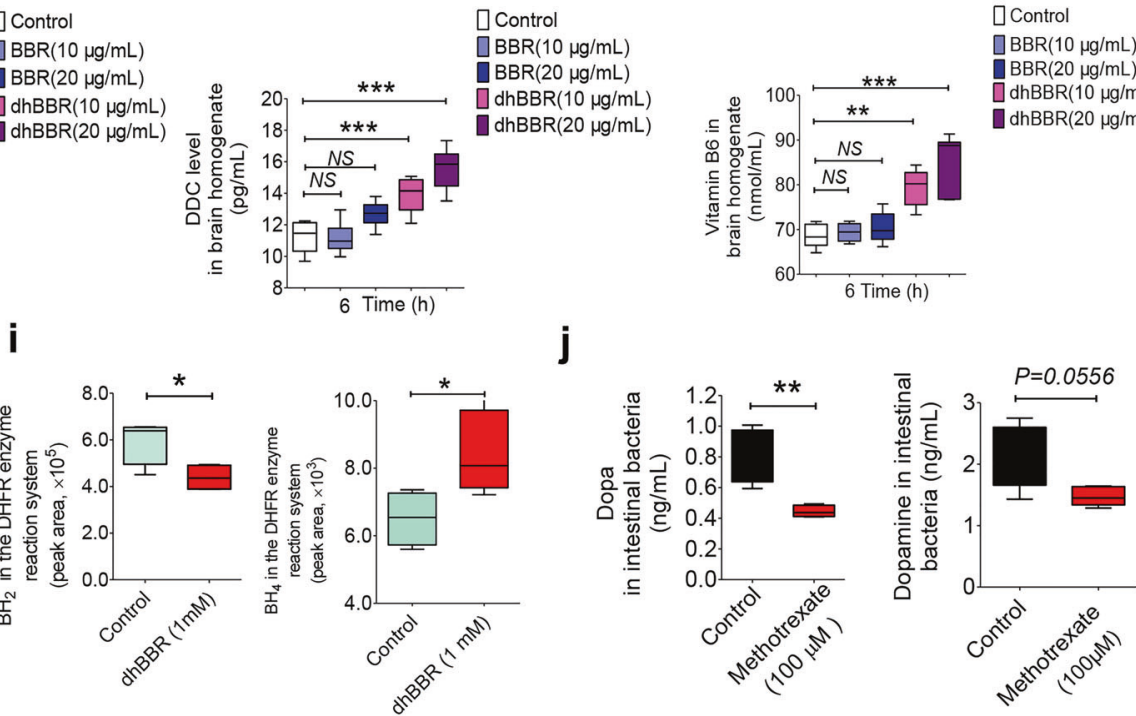

To learn whether the BBR-induced increase in dopa/dopamine could improve physical performance in animals, a brain functional test was performed in PD mouse models using established methods described previously. ${ }^{43}$ As shown in Fig. 5a, b, treating mice with both 1-methyl-4-phenyl-1,2,3,6-tetrahydropyridine hydrochloride (MPTP-HCL, $20 \mathrm{mg} / \mathrm{kg} / \mathrm{d}$, S.c.) and probenecid ( $P, 200 \mathrm{mg} / \mathrm{kg} / \mathrm{d}$, i.p.) for 7 days successfully generated damage in brain function, as demonstrated by a significant increase in latency to descent (LD, from 8 to $60 \mathrm{~s}$, $\left.{ }^{* * *} P<0.001\right)$, a decrease in latency to fall from rotarods (LFR, from 300 to $38 \mathrm{~s}$, $\left.{ }^{* *} P<0.001\right)$, and an increase by the ratio of ipsilateral touches to the total of ipsilateral and contralateral touches on the wall (separately counted) in the cylinder test (CT, from 27 to $72 \%$, ${ }^{* * P}<$ 0.01 ; Fig. $5 \mathrm{a}$ ) in the disease model mice. Treating the model mice with carbidopa ( $1 \mathrm{mg} / \mathrm{kg}$, s.c.) in combination with L-dopa (10 mg/ $\mathrm{kg} / \mathrm{d}$, s.c.) for 6 days (from days 2 to 7 ) decreased the time of LD from 60 to $18 \mathrm{~s}\left({ }^{* *} P<0.01\right)$, increased the LFR from 38 to $256 \mathrm{~s}$ ( ${ }^{* * *} P<0.001$ ), as well as decreased the ratio of CT from 72 to $35 \%$ $\left({ }^{* *} P<0.01\right)$, demonstrating a significant therapeutic effect of the Ldopa treatment. Treating the model mice orally with BBR $(200 \mathrm{mg} /$ 
Fig. 3 BBR activated the pathway for dopa/dopamine synthesis in the gut microbiota. a The activity of TH and DDC increased after treating the gut bacteria of SD rats with BBR at $12 \mathrm{~h}\left(10 \mu \mathrm{g} / \mathrm{mL},{ }^{*} P<0.05,{ }^{*} P<0.01\right)$, but weakened when TH inhibitor (BLMA5, $\left.100 \mu \mathrm{M}\right)$ or the DDC inhibitor (benserazide, $100 \mu \mathrm{M}$ ) was incubated with BBR as a whole (mean \pm SD, ${ }^{*} P<0.05,{ }^{* *} P<0.01$ ). The TH inhibitor BLMA or DDC inhibitor benserazide did not change the abundance of the intestinal bacteria at 50 or $100 \mu \mathrm{M}$. The activity of TH and DDC increased after treating the gut bacteria of SD rats with BBR at $12 \mathrm{~h}\left(10 \mu \mathrm{g} / \mathrm{mL},{ }^{*} P<0.05,{ }^{*} P<0.01\right)$, but weakened when the TH inhibitor (BLMA5, $\left.100 \mu \mathrm{M}\right)$ or DDC inhibitor (benserazide, $100 \mu \mathrm{M}$ ) was incubated with BBR as a whole (mean $\pm \mathrm{SD},{ }^{*} P<0.05,{ }^{* *} P<0.01$ ). b Levels of $\mathrm{BH}_{4}$ (the coenzyme of TH) increased significantly at 6 and $12 \mathrm{~h}$ after BBR or dhBBR treatment (10 and $20 \mu \mathrm{g} / \mathrm{mL}$, respectively) in SD gut bacteria in vitro (mean \pm SD, $+23 \% \uparrow,+31 \% \uparrow$ for BBR at $20 \mu \mathrm{g} / \mathrm{mL}$ at 6 and $12 \mathrm{~h},{ }^{* *} P<0.01,{ }^{* * *} P<0.001 ;+26 \% \uparrow,+34 \% \uparrow$ for dhBBR at $20 \mu \mathrm{g} / \mathrm{mL}$ at 6 and $\left.12 \mathrm{~h},{ }^{* *} P<0.01\right)$. In addition, the level of DDC coenzyme $\mathrm{VB}_{6}$ was enhanced in the intestinal bacteria at $12 \mathrm{~h}$ (mean $\pm \mathrm{SD},+16 \% \uparrow$ for $\mathrm{BBR}$ at $20 \mu \mathrm{g} / \mathrm{mL}, * * * P<0.001$; $+19 \% \uparrow$ for dhBBR at $20 \mu \mathrm{g} / \mathrm{mL}, * * P<0.01)$. c The TH inhibitor (BLMA5, $100 \mu \mathrm{M}$ ) decreased the production of dopa in SD rat gut bacteria when treated with BBR for 6 and $12 \mathrm{~h}\left({ }^{*} P<0.05,{ }^{*} P<0.01\right)$; DDC inhibitor (benserazide, $\left.100 \mu \mathrm{M}\right)$ also lowered the dopamine generation significantly when incubated with BBR (mean $\left.\pm \mathrm{SD},{ }^{* *} P<0.01,{ }^{* *} P<0.001\right)$. $\mathbf{d}$ The DDC inhibitor (benserazide, $100 \mu \mathrm{M}$ ) increased the generation of dopa in $S D$ rat gut bacteria when treated with $B B R$ (mean $\pm S D, * P<0.05$ ). e Levels of dopa/dopamine increased significantly at $6 \mathrm{hr}$ after dhBBR treatment in the brain homogenate of mice in vitro (mean $\pm \mathrm{SD},{ }^{* *} P<0.01,{ }^{* * *} P<0.001$ ). $\mathrm{f}$ Coincubation of mouse dopaminergic primary cells with BBR or dhBBR $(10 \mu \mathrm{g} / \mathrm{mL})$, significantly increased dopamine levels in the dopaminergic primary cells incubated with dhBBR $(* P<0.05)$. g Levels of TH/DDC increased significantly at $6 \mathrm{~h}$ after dhBBR treatment in the brain homogenate of mice in vitro (mean \pm SD, ${ }^{* *} P<0.01,{ }^{* * *} P$ $<0.001$ ). $\mathbf{h}$ Levels of $\mathrm{BH}_{4} / \mathrm{VB}_{6}$ increased significantly at $6 \mathrm{~h}$ after dhBBR treatment in the brain homogenate of mice in vitro (mean $\pm \mathrm{SD}$, ** $P<$ 0.01 , $\left.{ }^{* *} P<0.001\right)$. i BH 2 decreased significantly $\left({ }^{*} P<0.05\right)$ with increasing $\mathrm{BH}_{4}\left({ }^{*} P<0.05\right)$, when dhBBR was added to the mixture of $\mathrm{BH}_{2}($ as substrate) and dihydrobiopterin reductase at $37^{\circ} \mathrm{C}$ for $2 \mathrm{~h}$. $\mathrm{j}$ Levels of dopa/dopamine decreased significantly at $12 \mathrm{~h}$ after the treatment with DHFR inhibitor (methotrexate $100 \mu \mathrm{M}$ ) in the intestinal bacteria (mean $\pm \mathrm{SD}, * P<0.05$ )

$\mathrm{kg} / \mathrm{d}$ ) for 6 days (from days 2 to 7 ) significantly reduced the LD from 60 to $36 \mathrm{~s}(* * *<0.001)$, elevated the LFR from 38 to $92 \mathrm{~s}(* P$ $<0.05)$, and decreased the ratio in CT from 72 to $45 \%\left({ }^{*} P<0.05\right)$. I.p. injection of BBR (10 mg/kg, for 6 days) caused no significant change in the LD, LFR, or CT in the model mice. Chemical analysis showed that by day 7 of the experiment, dopa/dopamine in brain tissue was significantly higher in the BBR oral treatment group than that in the disease model mice $\left({ }^{*} P<0.05\right.$ for dopa, ${ }^{* * *} P<$ 0.001 for dopamine, Fig. 5b). The increase in dopa in the brains of mice treated with BBR was less significant than that of those treated directly with L-dopa plus carbidopa (Fig. 5b). It appears that in these mouse models, BBR partially ameliorated brain functional damage, and the elevation of dopa/dopamine production in the gut microbiota could be at least part of the mechanism. In this experiment, L-dopa treatment showed a therapeutic efficacy that was better than that of BBR, probably because of its combination use with carbidopa, a DDC inhibitor.

Transplantation of $E$. faecalis and $E$. faecium in animals increased brain dopa/dopamine and improved brain function

First, the enzymatic activity of TH and DDC level in the $E$. faecalis and $E$. faecium strains was detected. Considerable enzymatic activity of TH or DDC level was detected in both $E$. faecalis and $E$. faecium, in which the $\mathrm{TH}$ activity was 1.66 or $1.40 \mathrm{mU} / 10^{8}$ colony forming units (CFU) and DDC level was 0.65 or $0.62 \mathrm{pg} / 10^{8} \mathrm{CFU}$, respectively. No significant difference of the enzyme assay was observed between the two bacteria (Fig. S3i). Indeed, the two bacteria synthesized dopa/dopamine and the production was enhanced by BBR (Supplementary Fig. S3a, b).

We then transplanted E. faecalis and E. faecium into the PGF mice pretreated with antibiotics. Their intestinal bacterial colony number was decreased by $89 \%$ on average, which was significantly lower than that of the untreated mice $(* * * P<0.001$, Fig. 5c).

Then, the mice were randomly divided into seven groups $(n=$ 6 per group). Normal mice treated with PBS were in group 1, as control. Group 2 was treated with antibiotics only as the PGF reference (control); group 3 was treated with BBR $(200 \mathrm{mg} / \mathrm{kg} / \mathrm{d}$, oral); group 4 was treated with $E$. faecalis $\left(6 \times 10^{8} \mathrm{CFU} / \mathrm{d}\right.$, oral) alone; group 5 was treated with E. faecalis and BBR $(200 \mathrm{mg} / \mathrm{kg} /$ d, oral); group 6 was treated with E. faecium $\left(6 \times 10^{8} \mathrm{CFU} / \mathrm{d}\right.$, oral) alone; and group 7 was treated with $E$. faecium and BBR $(200 \mathrm{mg} / \mathrm{kg} / \mathrm{d}$, oral). The mice in the groups $2-7$ were orally given antibiotics (see the "Method" section) twice a day for 3 days in advance, and then BBR $(200 \mathrm{mg} / \mathrm{kg})$ and/or bacteria were orally given to five of the groups (groups 3-7) for successive 3 days. Three days after bacterial transplantation, the brain, blood, and feces were collected for dopa and dopamine measurement. We should mention here that in the early experiments of bacterial transplantation, we found that the transplanted bacteria had successfully colonized in mouse intestine, for example, in E. faecium transplantation $\left({ }^{*} P<0.05\right.$; Fig. S3j), ensuring the prerequisite of the experiment.

As shown in Fig. 5d-f, 3 days after $E$. faecalis and E. faecium transplantation, the levels of dopa/dopamine in brain, blood, and feces of the PGF mice were considerably increased, compared to those in the PGF mice (group 2). The mice treated with $E$. faecium showed an elevation of $14 \%$ in brain dopa (group 6 vs. group 2, in Fig. $5 d(L))$ and a significant increase of $22 \%$ in brain dopamine (group 6 vs. group 2, in Fig. $\left.5 \mathrm{~d}(\mathrm{R}),{ }^{*} P<0.05\right)$. In addition, dopa in blood increased by $28 \%$ (group 6 vs. group 2 , in Fig. $5 \mathrm{e}(\mathrm{L})$, ${ }^{* *} P<$ 0.01 ), dopamine increased by $10 \%$ (group 6 vs. group 2, in Fig. $5 \mathrm{e}$ (R)), dopa in feces increased by $15 \%$ (group 6 vs. group 2, in Fig. $5 f$ (L), ${ }^{*} P<0.01$ ), and dopamine increased by $25 \%$ (group 6 vs. group 2 , in Fig. $5 f(R), * * P<0.01)$. For the mice with $E$. faecalis, the levels of dopa/dopamine were also elevated in the brain, blood, and feces of the mice (group 4 vs. group 2, Fig. $5 d-f$ ), but not as high as those with $E$. faecium, suggesting that the ability of synthesizing dopa/dopamine in $E$. faecium was slightly stronger than that of $E$. faecalis (group 6 vs. group 4, in Fig. 5d-f). In additionally, E. coli was transplanted into the PGF mice for comparison. As shown in Figs. S4a-C, 3 days after E. coli transplantation, the levels of dopa/ dopamine in brain, blood, and feces of the PGF mice remained unchanged, while the mice treated with $E$. faecium and $E$. faecalis showed a significant increase in dopa/dopamine in the brain, consistent with the in vitro results (in Fig. S3a, b). Considering that $\mathrm{TH}$-mediated biochemical reactions require the presence of ROS, ${ }^{44}$ ROS in the intestinal bacteria was measured. The results showed that ROS were detectable in E. coli, E. faecium, and E. faecalis, with which TH could convert tyrosine into L-dopa $\left({ }^{*} P<0.05\right.$, ${ }^{*} P<0.01$, and ${ }^{* * *} P<0.001$; Fig. S3k).

BBR treatment did not increase the levels of dopa/dopamine in the PGF mice (group 3 vs. group 2, NS, Fig. $5 d-f$ ), but promoted either $E$. faecalis or E. faecium to synthesize dopa/dopamine in the PGF mice. As shown in Fig. $5 d(\mathrm{R})$, E. faecium combined with BBR increased brain dopamine by $15 \%$ (group 7 vs. group 6 , ${ }^{*} P<0.05$ ) compared with $E$. faecium alone, which may be due to the stimulation effect of BBR on the intestinal bacteria TH and DDC. In addition, combination of BBR with $E$. faecium increased brain dopamine by $36 \%$ (group 7 vs. group $3,{ }^{*} P<0.01$, Fig. $5 d(R)$ ) and brain dopa by $28 \%$ (group 7 vs. group $3,{ }^{*} P<0.05$, Fig. $5 d(L)$ ) compared with those in the PGF mice with BBR alone. BBR plus $E$. faecalis also resulted in an increase in brain dopamine by $22 \%$ (group 5 vs. group 3, Fig. $5 d(R),{ }^{*} P<0.05$ ) and brain dopa by $20 \%$ 


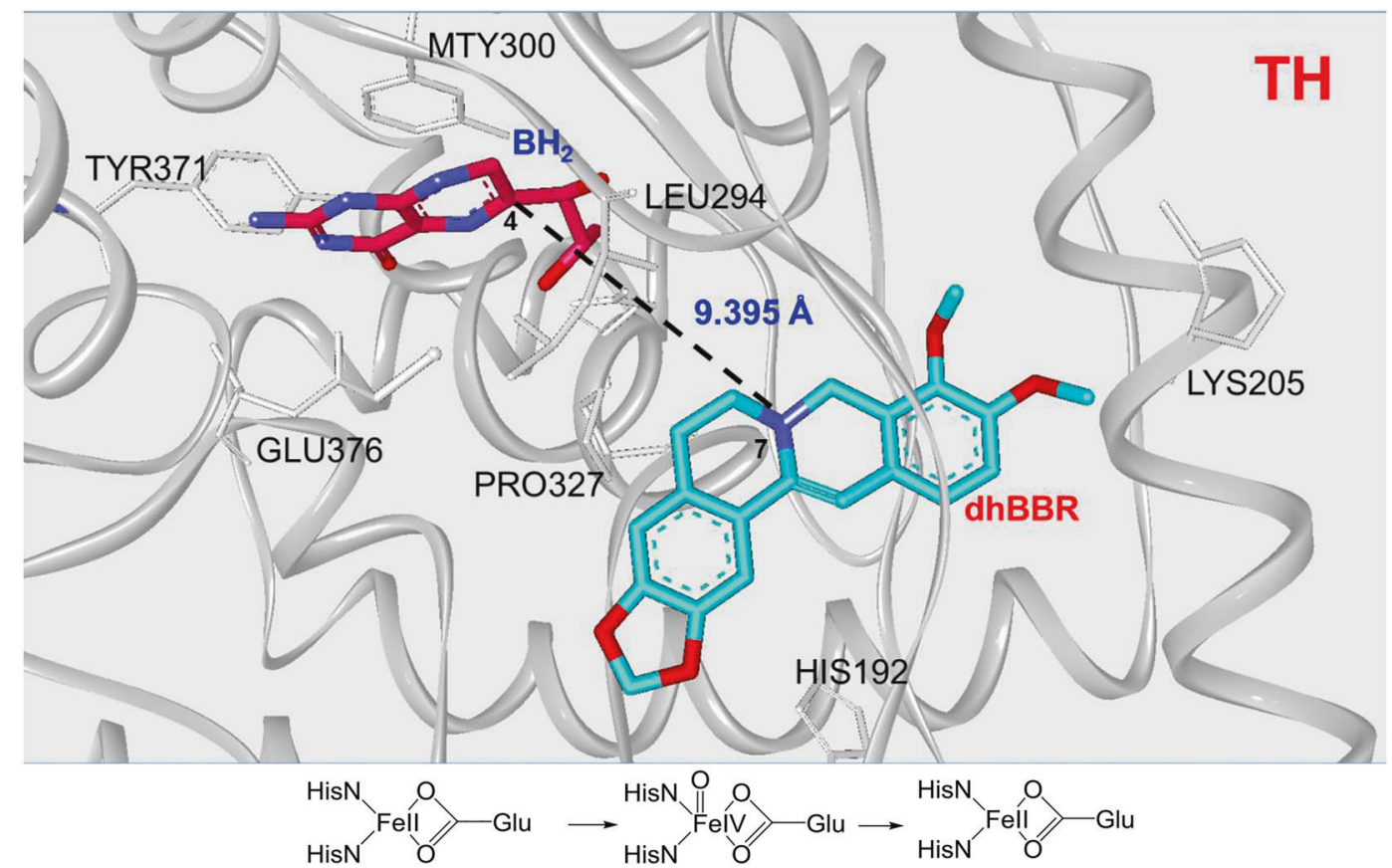

Chemical form of $\mathrm{Fe}$ (II) Chemical form of $\mathrm{Fe}(\mathrm{IV}) \mathrm{O}$ Chemical form of $\mathrm{Fe}$ (II)

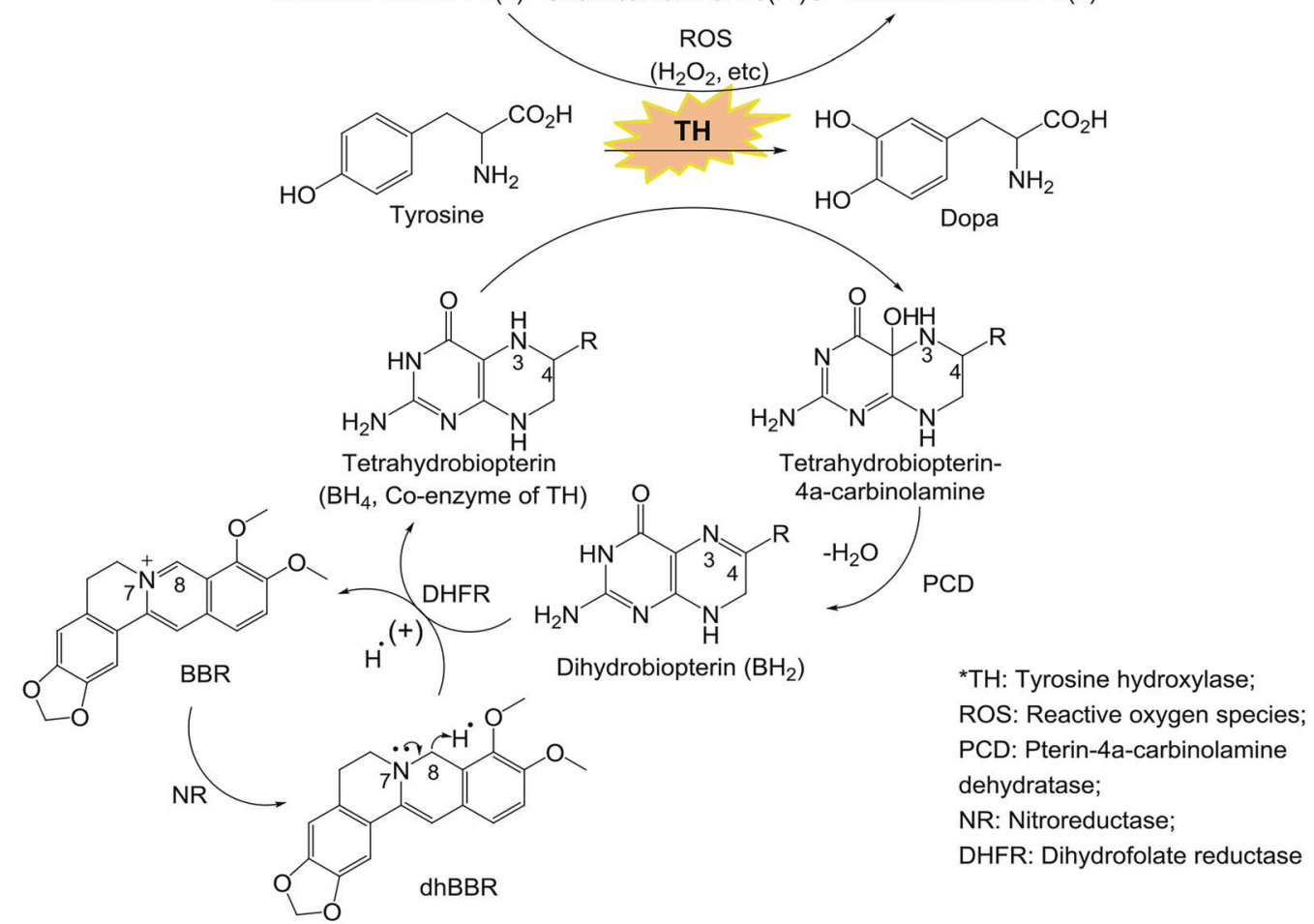

Fig. 4 The dhBBR-mediated chemical reaction for the conversion from tyrosine to dopa. $\mathrm{BH}_{2}$ obtained $\mathrm{H}^{\circ}$ from the dhBBR-BBR system, and its reduction was activated, in which $\mathrm{H}^{\circ}$ from dhBBR $\left(\mathrm{N}_{7}-\mathrm{C}_{8}\right)$ moved to the $\mathrm{N}_{3}=\mathrm{C}_{4}$ bond in $\mathrm{BH}_{2}$, and $\mathrm{N}_{3}=\mathrm{C}_{4}$ was then transformed into $\mathrm{N}_{3}-\mathrm{C}_{4}\left(\mathrm{BH} \mathrm{H}_{2}\right.$ was converted into $\mathrm{BH}_{4}$ ). In the meanwhile, dhBBR lost $\mathrm{H}^{\circ}$, and was oxidized into $\mathrm{BBR}$. The increased $\mathrm{BH}_{4}$ in intestinal bacteria accelerates the transformation from tyrosine to L-dopa, in the presence of $\mathrm{ROS}\left(\mathrm{H}_{2} \mathrm{O}_{2}\right.$, etc.) as well as $\mathrm{Fe}^{2+}$. $\mathrm{Accordingly} \mathrm{BH}_{4}$ is converted into tetrahydrobiopterin- $4 \alpha$-carbinolamine

(group 5 vs. group 3, Fig. $5 d(L)$ ). Levels of dopa/dopamine in plasma or feces showed an escalation profile similar to that in brain (Fig. 5e, f; group 5 vs. group 3, group 7 vs. group 3 , ${ }^{* *} P<0.01$ and ${ }^{*} P<0.05$, respectively).

As we have seen in Fig. $5 \mathrm{~d}-\mathrm{f}$, treatment with antibiotics could reduce the bacterial colony in the mouse intestine; however, dopa and dopamine in the feces, plasma, and brain of the PGF mice did not change significantly. The explanation could be first that gut microbiota might not be the major contributor for brain dopamine in nature; thus, dopamine level in brain and blood is relatively stable, even the bacterial colony numbers decreased; and second, Enterococcus appeared relatively more resistant to the antibiotics as compared with other bacteria in intestine (Supplementary Fig. $\mathrm{S} 3 \mathrm{j})$, thus the residual Enterococcus remains good production of dopa/dopamine. Other reasons might not be excluded. Actually, dopamine level in brain was decreased by antibiotics $\sim 10 \%$ 
a

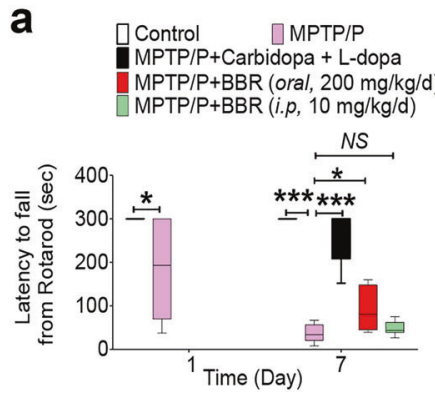

b
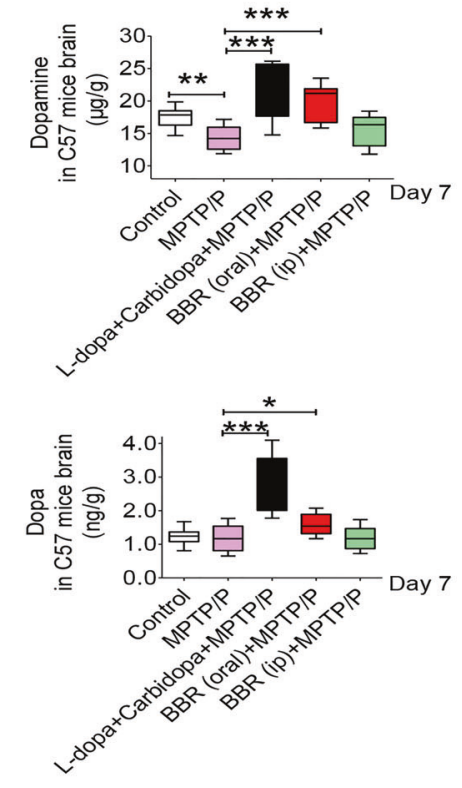

C
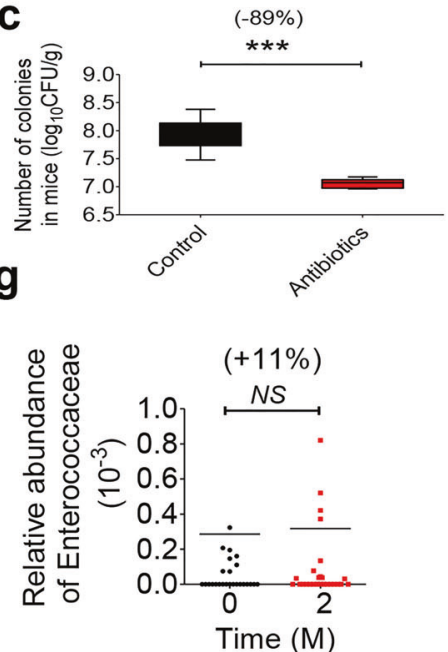

Control $\quad \square$ MPTP/P
MPTP/P+Carbidopa + L-dopa

MPTP/P+Carbidopa + L-dopa
MPTP/P+BBR (oral, $200 \mathrm{mg} / \mathrm{kg} / \mathrm{d})$

MPTP/P+BBR $(i . p, 10 \mathrm{mg} / \mathrm{kg} / \mathrm{d})$

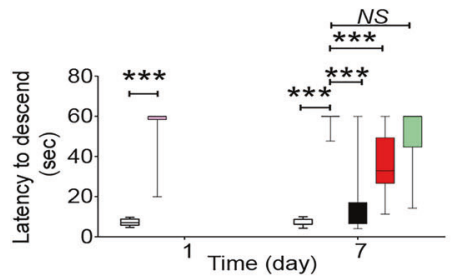

d $(L)$

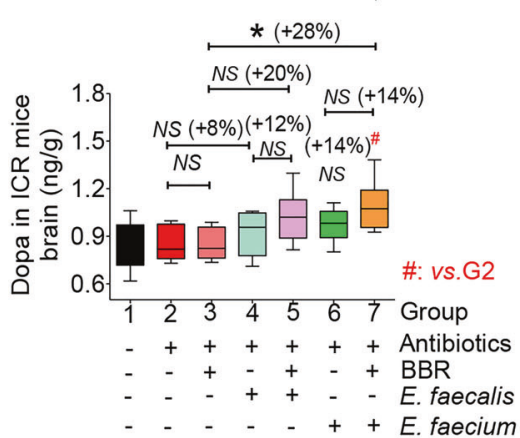

e $(L)$
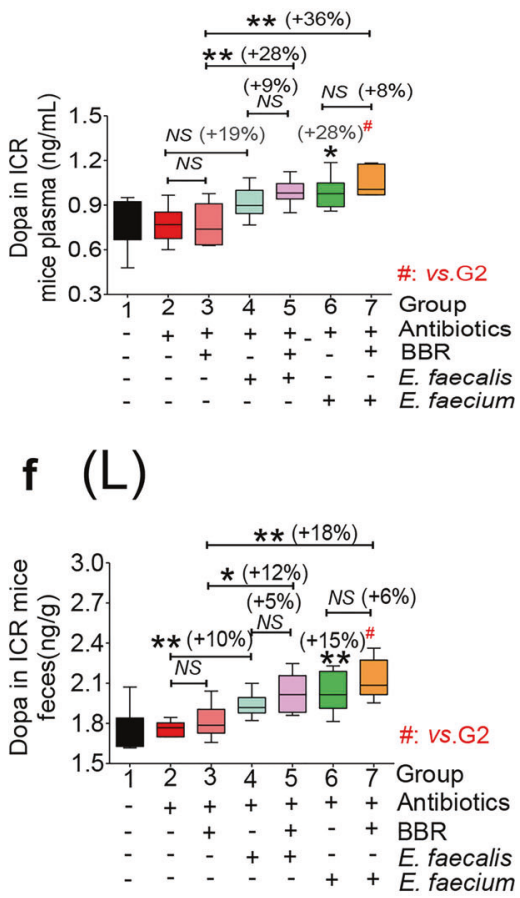

Control $\quad \square$ MPTP/P

MPTP/P+Carbidopa + L-dopa

MPTP/P+BBR (oral, $200 \mathrm{mg} / \mathrm{kg} / \mathrm{d}$ )

MPTP/P+BBR (i.p., $10 \mathrm{mg} / \mathrm{kg} / \mathrm{d}$ )

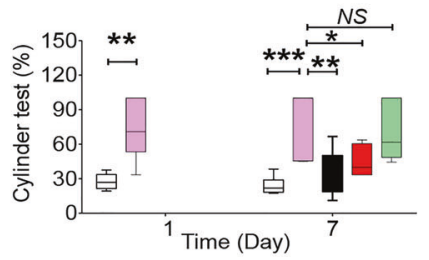

$(\mathrm{R})$

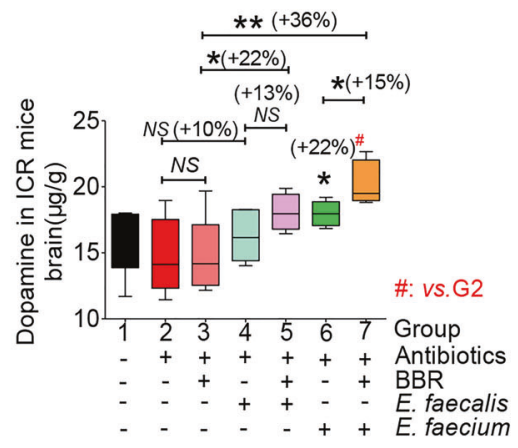

$(\mathrm{R})$

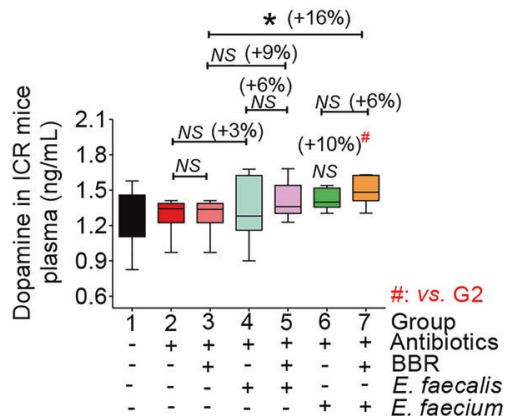

$(\mathrm{R})$

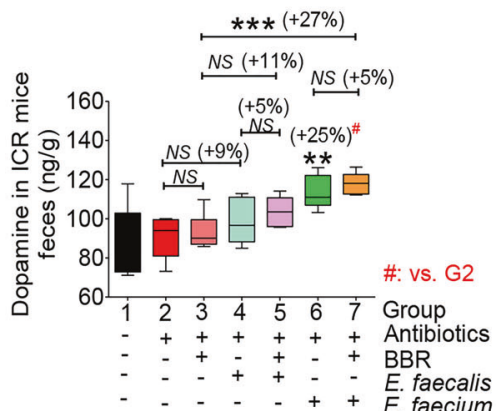

Fig. 5 E. faecalis and $E$. faecium regulated dopa/dopamine and improved brain function in PD animals in the presence of BBR. a Treating mice with both MPTP $(20 \mathrm{mg} / \mathrm{kg} / \mathrm{d}$, s.c.) and P $(200 \mathrm{mg} / \mathrm{kg} / \mathrm{d}$, i.p.) for 7 days successfully generated the damage to brain function (LD, ***P<0.001; LFR, $\left.{ }^{* * *} P<0.001\right)$ in the model mice. Carbidopa $(1 \mathrm{mg} / \mathrm{kg}$, s.c.) in combination with L-dopa $(10 \mathrm{mg} / \mathrm{kg} / \mathrm{d}$, s.c.) for 6 days (from days 2 to 7$)$ decreased the LD, cylinder test value ${ }^{* * *} P<0.001$, $\left.{ }^{* *} P<0.01\right)$, and increased the LFR (***P<0.001); BBR (200 mg/kg/d, orally, days 2 to 7$)$ significantly reduced the LD, cylinder test value ( $\left.{ }^{* * *} P<0.001,{ }^{*} P<0.05\right)$, and elevated the LFR ( $\left.P<0.05\right)$. Intravenous injection of BBR (10 mg/ $\mathrm{kg}$, for 6 days) did not cause a significant change in the LD, LFR, or cylinder test. $\mathbf{b}$ Levels of dopa/dopamine in the brain on day 7 of the experiment (mean $\pm S D,{ }^{*} P<0.05$ for dopa; ${ }^{* *} P<0.01$, ${ }^{* *} P<0.001$ for dopamine). c Number of colonies from the mice treated with the antibiotics was significantly lower than that from the normal mice (mean $\pm \mathrm{SD},{ }^{* * *} P<0.001$ ). $\mathbf{d}-\mathbf{f}$ Translation of $E$. faecalis and $E$. faecium into the mice treated with antibiotics significantly increased dopa (L)/dopamine (R) levels in ICR mouse brains (d, ${ }^{*} P<0.05,{ }^{* *} P<0.01, \mathrm{NS}$ no significance), blood (e, $\left.{ }^{*} P<0.05,{ }^{*} P<0.01\right)$, and feces $\left(\mathbf{f},(\mathrm{L}),(\mathrm{R}),{ }^{*} P<0.05,{ }^{*} P<0.01,{ }^{* *} P<0.001\right)$. $\mathbf{g}$ The relative abundance of Enterococcaeae in the fecal samples of clinical subjects increased after the two-month BBR treatment. Data are represented as the mean \pm SD 
evidenced in the brain dopamine test (Fig. $5 d(R),-7.8 \%)$, as well as in the ${ }^{15} \mathrm{~N}$-labeled experiment (Supplementary Fig. S2f, $-17.2 \%)$.

These results suggested that $E$. faecalis or E. faecium might play a key role in synthesizing dopa and dopamine if transplanted into the body; BBR treatment could activate the TH and DDC enzymes of the bacteria and enhance dopa/dopamine production in the intestine, eventually resulting in elevated dopa/dopamine in the brain. Accordingly, the behavioral improvement was observed in the PD model mice treated with the bacteria and BBR (Supplementary Fig. S5a, b and S6a-c).

2,4,6-Trimethyl-pyranylium tetrafluoroborate-derivatized matrixassisted laser desorption mass spectrometry imaging of dopamine in ICR mouse brains

To further demonstrate that the interaction between BBR and $E$. faecalis/E. faecium benefits dopamine generation, we employed TMPTFB-derivatized MALDI-MS imaging method to investigate the distribution of striatal dopamine in each group. ${ }^{45}$ Eighteen ICR mice (male, 18-22 g) were randomly divided into six groups, namely groups 1-6. The mice in groups 1 and 2 were treated with PBS, and the mice in group 3 were treated with $E$. faecalis $\left(6 \times 10^{8} \mathrm{CFU} / \mathrm{d}\right.$, oral); the mice in group 4 were treated with $E$. faecalis and BBR $(200 \mathrm{mg} /$ $\mathrm{kg} / \mathrm{d}$, oral); the mice in group 5 were treated with $E$. faecium $\left(6 \times 10^{8}\right.$ CFU/d, oral); and the mice in group 6 were treated with $E$. faecium and BBR $(200 \mathrm{mg} / \mathrm{kg} / \mathrm{d}$, oral). The mice in groups 2-6 were orally given cefadroxil $(100 \mathrm{mg} / \mathrm{kg})$, terramycin $(300 \mathrm{mg} / \mathrm{kg})$, and erythromycin $(300 \mathrm{mg} / \mathrm{kg})$ twice a day for 3 days, and then BBR or bacteria was orally given to the four groups for three successive days.

As shown in Fig. 6, the results are presented in four different ways, including the relative abundance and distributions of dopamine with a spatial resolution of $200 \mu \mathrm{m}$ (Fig. 6a); rescaled image from Fig. 6a with baseline subtraction and total ion count normalization (Fig. 6b); the relative abundance and distributions of dopamine with a spatial resolution of $100 \mu \mathrm{m}$ (Fig. 6c); and the relative abundance and distributions of dopamine in half the brain from the same mice in Fig. $6 \mathrm{c}$ with a spatial resolution of $200 \mu \mathrm{m}$ (Fig. 6d). Compared to groups 3 and 5, in which the mice were only treated with bacteria, the striatal dopamine levels in the mice that received both bacteria, and BBR were much higher from the perspective of both the whole brain and half brain (Fig. 6a-d). This result is consistent with what we obtained with brain homogenate (Fig. $5 e(R)$ ), which demonstrated that BBR might have the potential to stimulate the dopa/dopamine pathways of $E$. faecalis and $E$. faecium by increasing $\mathrm{BH}_{4}$ levels in the intestine. This interaction eventually leads to an elevated amount of dopamine in the brain, of which combination of BBR with $E$. faecalis or E. faecium showed an elevation higher than that treated with $E$. faecalis or $E$. faecium alone (Fig. 6a-d).

BBR increased blood dopa/dopamine in clinical subjects

To learn whether BBR could increase blood dopa in humans, 28 individuals with hyperlipidemia were randomly enrolled in the BBR treatment study in the Outpatient Section of the First Hospital of Jilin University in Changchun in the early spring of 2017 (Clinical approval number ChiCTR-OPN-17012942).

As the first step of the trial, blood, and fecal samples of the 28 subjects were taken for the baseline. Then, BBR $(0.5 \mathrm{~g}$, bid) was orally given to the subjects for 8 weeks, followed by sample collection (blood and fecal samples). As shown in Table 1, after 8 weeks of BBR therapy, blood dopa/dopamine was elevated (dopa, NS, $+17 \% \uparrow$; dopamine, ${ }^{*} P<0.05,+24 \% \uparrow$ ). Fecal tests demonstrated results similar to those of blood, showing an increase in dopa and dopamine in feces (dopa, ${ }^{* *} P<0.001$, $+46 \% \uparrow$; dopamine, ${ }^{* * *} P<0.001,+47 \% \uparrow$, Table 1). Meanwhile, $\mathrm{TH}$ and DDC in gut microbiota were upregulated by BBR $\left(\mathrm{TH},{ }^{* *} P<\right.$ $0.001,+42 \% \uparrow ;$ DDC, NS, $+20 \% \uparrow$, Table 1). The results agreed with those detected in the animal experiments. Analysis of the microbial diversity in the fecal samples of 28 clinical patients showed that, after 2 months of BBR treatment, the relative abundance of Enterococcus increased by $11 \%$ (Fig. $5 \mathrm{~g}$; Table 1), in which E. faecalis and $E$. faecium were predominant. ${ }^{46}$ The results further validated that Enterococcus might be an interesting genus for dopa/ dopamine biosynthesis in the intestine, and BBR might promote the body dopa/dopamine levels through the bacteria in intestine.

\section{DISCUSSION}

BBR is an alkaloid that is poorly absorbed in the intestine, ${ }^{31-33,47}$ but it has been well documented by independent groups that oral administration of BBR showed therapeutic effects on energy metabolism and brain function in patients, as well as in animals, ${ }^{48}$ leaving us with a very interesting question in pharmacological research. We have recently discovered that BBR could stimulate synthetic pathways in gut microbiota to produce short-chain fatty acids, such as acetate, propionate, and butyrate, which steadily enter the blood and lower blood lipids and sugar. ${ }^{49}$ In continuing the searching for BBR-induced bioactive metabolites from gut microbiota, we discovered that the concentrations of Tyr, dopa, and dopamine significantly increased in the intestinal bacteria after exposure to BBR, while Phe decreased. The activity of TH and DDC in gut flora might play an important role in the mode of action of BBR. The key chemical mechanism appears to be associated with the intestinal $\mathrm{dhBBR}$, which accelerates the transformation from $\mathrm{BH}_{2}$ to $\mathrm{BH}_{4}$ by contributing $\mathrm{H}^{\circ}$, leading to an increase in $\mathrm{BH}_{4}$ levels and then $\mathrm{TH}$ activity.

$\mathrm{BH}_{4}$ is a coenzyme of either $\mathrm{TH}$ or $\mathrm{PAH}$ acting as an electron carrier in enzymatic reactions as a reducing agent. ${ }^{11}$ The oxidation form of $\mathrm{BH}_{4}$ is $\mathrm{BH}_{2}$, and $\mathrm{BH}_{4}$ can be regenerated by NADPH as a hydrogen donor under the catalysis of DHFR. ${ }^{11} \mathrm{~A}$ deficiency of $\mathrm{BH}_{4}$ or the reductase will directly inhibit the hydroxylation of Phe to Tyr and/ or Tyr to dopa, which will block the Phe-Tyr-dopa-dopamine metabolism pathway and lead to nervous system diseases. ${ }^{50}$ At present, the main clinical treatment strategy for $\mathrm{BH}_{4}$ deficiency is to increase the intake of synthetic $\mathrm{BH}_{4}$ (trade name Kuvan). ${ }^{51}$ Here, BBR might be the first agonist of Enterococcus bacteria that leads to the production of L-dopa by triggering $\mathrm{BH}_{4}$ formation in the gut bacteria. Interestingly, BBR acts in a way similar to vitamins. The molecular details are illustrated in Fig. 4.

Furthermore, BBR could promote dopa/dopamine production through improving the Phe-Tyr-dopa-dopamine synthetic pathway in gut flora, but not in other tissues (liver, small intestine, and brain; Fig. 3e and Supplementary Fig. S3e-g), suggesting that the active compound for dopa/dopamine production is dhBBR, which is converted from BBR by nitroreductase in the intestinal bacteria $^{33}$ and is almost undetectable in blood. Indeed, dopa/ dopamine in brain tissue was increased by dhBBR, but not BBR (Fig. 3e). Biochemical studies of the intestinal bacteria revealed that BBR/dhBBR activated bacterial TH, DDC enzymes through their cofactors $\mathrm{BH}_{4}$ and $\mathrm{VB}_{6}$ (Fig. $3 \mathrm{~b}, \mathrm{~g}, \mathrm{~h}$ ), thus efficiently metabolizing dietary Phe into Tyr, and then dopa/dopamine in intestinal cavity (Table 1).

In addition, the proportion of dopa/dopamine-producing bacteria in the gut flora community was also increased after exposure to BBR, indicating a favorable selection of BBR in the gut flora community. BBR-induced intestinal Tyr, dopa, and dopamine entered the blood and eventually showed an increased concentration of dopamine in the brain. Accordingly, brain function in mice injured by injection of MPTP and $P$ was in part protected by BBR oral treatment, at least partially due to the increase in dopamine in the brain. The increased dopa and dopamine levels were further detected in the blood of patients who took BBR for 2 months. The clinical study was performed in patients with hyperlipidemia, as it has been reported that patients with metabolic disorders have a higher incidence of developing neurodegenerative diseases, as compared to those with normal 


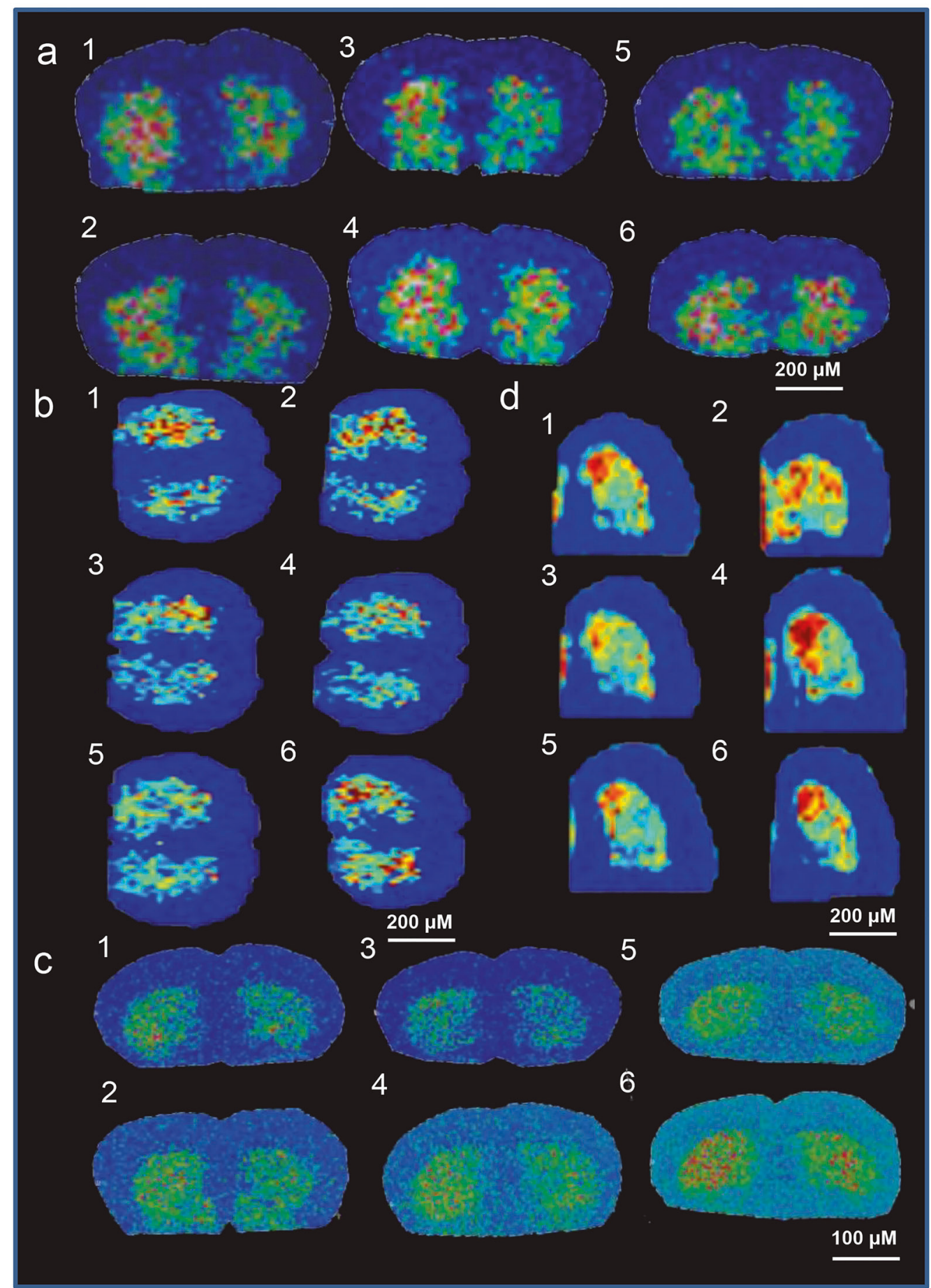

Fig. 6 BBR stimulated the production of dopamine in striatum in mice transplanted with $E$. faecalis or $E$. faecium: TMP-TFB-derivatized MALDIMS images. a The relative abundance and distributions of dopamine with a spatial resolution of $200 \mu \mathrm{m}$. $\mathbf{b}$ Rescaled image from a with baseline subtraction and total ion count normalization. c The relative abundance and distributions of dopamine with a spatial resolution of $100 \mu \mathrm{m}$. d The relative abundance and distributions of dopamine in half brains from the same mice in c with a spatial resolution of $200 \mu \mathrm{m}$. All of them showed elevated levels of dopamine after BBR addition. (group 1: normal group; group 2: antibiotic treated only; group 3: antibiotics and E. faecalis; group 4: antibiotics, E. faecalis, and BBR (200 mg/kg); group 5: antibiotics, E. faecium; and group 6: antibiotics, E. faecium, and BBR $(200 \mathrm{mg} / \mathrm{kg}))$. Blue represents the decreased level and red represents the increased level. The striatal dopamine level in the mice receiving both $E$. faecalis and BBR was higher than that treated with E. faecalis only (group 3 vs. group 4). The striatal dopamine in the mice receiving both $E$. faecium and BBR was higher than that treated with $E$. faecium only (group 5 vs. group 6) 
Table 1. Berberine regulated the biomarkers in blood and feces of clinical subjects ${ }^{\mathrm{a}}$

\begin{tabular}{|c|c|c|c|}
\hline \multirow[t]{2}{*}{ Biomarker } & \multicolumn{3}{|c|}{ In blood (mean $\pm S D, n=28)$} \\
\hline & Untreated $^{\mathrm{b}}$ & $\begin{array}{l}\text { Treated } \\
\text { with } \mathrm{BBR}^{\mathrm{c}}\end{array}$ & $\begin{array}{l}(\mathrm{c}-\mathrm{b}) / \\
\mathrm{b} \times 100 \%\end{array}$ \\
\hline Dopa (ng/mL) & $1.10 \pm 0.45$ & $1.29 \pm 0.36^{\mathrm{ns}}$ & $+17 \% \uparrow$ \\
\hline Dopamine (ng/mL) & $1.40 \pm 0.48$ & $1.73 \pm 0.67^{*}$ & $+24 \% \uparrow$ \\
\hline \multirow[t]{2}{*}{ Biomarker } & \multicolumn{3}{|c|}{ In feces (mean $\pm S D, n=28)$} \\
\hline & Untreated $^{d}$ & $\begin{array}{l}\text { Treated } \\
\text { with } \mathrm{BBR}^{\mathrm{e}}\end{array}$ & $\begin{array}{l}(e-d) / d \times \\
100 \%\end{array}$ \\
\hline Dopa (ng/mL) & $1.64 \pm 0.48$ & $\begin{array}{l}2.39 \pm \\
0.74^{* * * *}\end{array}$ & $+46 \% \uparrow$ \\
\hline Dopamine (ng/mL) & $80.47 \pm 21.43$ & $\begin{array}{l}118.51 \pm \\
39.75^{* * *}\end{array}$ & $+47 \% \uparrow$ \\
\hline TH (U/L) & $7.07 \pm 1.74$ & $\begin{array}{l}10.05 \pm \\
4.05^{* *}\end{array}$ & $+42 \% \uparrow$ \\
\hline $\mathrm{DDC}(\mathrm{pg} / \mathrm{g})$ & $1.88 \pm 0.31$ & $2.25 \pm 0.90^{\mathrm{ns}}$ & $+20 \% \uparrow$ \\
\hline $\begin{array}{l}\text { Relative abundance of } \\
\text { Enterococcaceae (\%) }\end{array}$ & $\begin{array}{l}0.0286 \pm \\
0.0133^{f} \\
\end{array}$ & $\begin{array}{l}0.0318 \pm \\
0.0178^{f} \\
\end{array}$ & $+11 \% \uparrow$ \\
\hline \multicolumn{4}{|c|}{$\begin{array}{l}\text { ns no significant } \\
{ }^{*} P<0.05, * * P<0.01, * * * P<0.001 \\
{ }^{a} \text { Clinical subjects: oral, } 1 \mathrm{~g} / \mathrm{d} \text {, for } 60 \text { days; data are shown as mean } \pm \mathrm{SD} \text {. } \\
{ }^{\mathrm{b} B i o m a r k e r} \text { levels in blood of untreated subjects. 'Biomarker levels in } \\
\text { blood of sujects treated with BBR. }{ }^{\mathrm{d}} \text { Biomarker levels in feces of untreated } \\
\text { subjects. }{ }^{\mathrm{e} B i o m a r k e r ~ l e v e l s ~ i n ~ f e c e s ~ o f ~ s u b j e c t s ~ t r e a t e d ~ w i t h ~ B B R ~} \\
{ }^{\mathrm{f} D a t a} \text { are shown as mean } \pm \mathrm{SEM}\end{array}$} \\
\hline
\end{tabular}

metabolic profiles. ${ }^{52-55}$ The clinical results showed an improved blood level of dopa/dopamine by BBR, of which dopa could enter the brain, be converted into dopamine and improve brain function. To the best of our knowledge, this is the first report to show that regulation of the Phe-Tyr-dopa-dopamine pathway axis in the gut microbiota by a drug could improve brain function. The pathway intermediates (especially dopa) might be the chemical link for the crosstalk between gut and brain (Figs. 4 and and 7). ${ }^{56}$

Dopamine is a catecholamine neurotransmitter that plays key roles in motor coordination, as well as motivation, reward, addiction, learning, and memory. Dopaminergic neurons synthesize, secrete, reuptake, and metabolize dopamine using a group of enzymes and transporters. Secreted dopamine interacts with its receptors on postsynaptic neurons and adjusts intracellular signaling pathways. ${ }^{57}$ Currently, five subtypes of dopamine receptors $\left(D_{1}-D_{5}\right)$ are documented. The receptor subtypes have distinct anatomical distributions in different areas of the brain ${ }^{58}$ and might be considered biomarkers for various clusters of dopamine-related functions. ${ }^{59}$ Dopamine deficiency (or loss of dopamine-secreting cells) in CNS disorders, such as depression and PD, correlates with functional decline in memory, cognition, motivation, and motor control. ${ }^{59}$ In fact, during the normal aging process, brain dopamine levels are known to decrease by $\sim 7 \%$ per decade, ${ }^{59}$ suggesting an important role of dopamine in brain function. Actually, evidence has linked an increase in dopamine to a positive mood, as well as improved executive function. ${ }^{60}$ The present study identifies the gut microbiota as a novel dopa/ dopamine-producing "organ" in addition to the brain and discovers BBR a stimulating agent for dopa/dopamine production in the intestinal bacteria. These results also provided support, in view of the mechanism, for the previous observation that oral administration of BBR showed a positive effect on learning and memory. ${ }^{61}$ It appears that regulating the production of neurotransmitters by the gut microbiota (by drugs, food, or nutrients) might improve brain function (or EQ in humans).

As a dopamine precursor, L-dopa has been used as a first-line drug to treat patients with PD for decades ${ }^{13,62}$ and as a DCC inhibitor carbidopa is used together with L-dopa to increase the blood concentration of L-dopa. ${ }^{63}$ L-Dopa is able to cross the blood-brain barrier and enter brain tissue. The central transformation from L-dopa to dopamine likely takes place at surviving dopaminergic terminals and at serotonergic and adrenergic nerve terminals that contain decarboxylase. ${ }^{64}$ The therapeutic effect of Ldopa comes from restoration of the extracellular dopamine level in the dorsal striatum area, which is deficient in endogenous dopamine as a consequence of the neurodegenerative course in PD. ${ }^{65}$ A recent study showed that L-dopa can also restore the striatal activity and improve decision performance in some older adults. $^{13,66}$ However, many patients develop dyskinesias and motor fluctuations within a few years after L-dopa therapy. ${ }^{67}$ In the late stages of PD, L-dopa might induce nonmotor fluctuations with cognitive dysfunction and neuropsychiatric symptoms. ${ }^{65}$ Several presynaptic mechanism studies showed that some of the adverse events of L-dopa might be linked to the large dopamine swings in the brain, concomitant with the peaks and troughs of plasma Ldopa levels. ${ }^{67}$ In the present study, we showed a moderate and constant increase in the dopa/dopamine concentration in the blood and brain (Fig. 1b, c) in animals orally treated with BBR. This is most likely due to the restricted dopa/dopamine-producing capacity in the gut microbiota, and the steady interaction between BBR and bacteria in the intestine, causing a gentle but stable and continuous rise in dopamine in the brain (compared to L-dopa). It might be an advantage in reducing the chance of adverse effects with long-term therapy. Furthermore, in Fig. 3d, we showed that combining BBR with DDC inhibitor benserazide produced an extra increase in dopa in culture, suggesting a BBRrelated drug combination for the treatment of PD in the future.

Enterococcus is the host bacteria in the gastrointestinal tract. Belonging to Enterococcus, E. faecium, and E. faecalis strains have been used as probiotics to treat diarrhea, antibiotic-associated diarrhea, or irritable bowel syndrome; to lower cholesterol levels; and to improve host immunity. ${ }^{21,68-74}$ In the present study, we found that $E$. faecalis and E. faecium contained TH and DDC activity. In fact, a number of bacteria have several means to complete the action of TH and DDC. Through searching the NCBI database, we found bacteria positive for homologs of the TH gene; for instance, Ralstonia solanacearu and Streptomyces achromogenes contain TH (GenBank: CAD13865.1 and GenBank: ACN39022.1). Tyrosinase present in bacteria (such as Pseudomonas and Bacillus) could also convert tyrosine into L-dopa. ${ }^{75-77}$ In fact, after searching the NCBI database for protein functions in Enterobacter, we found two protein sequences for hydroxylase and ten for decarboxylase in the E. faecalis (coded no. WP_077497585.1, WP_002362599.1, as well as WP_002414512.1,WP_002388973.1,WP_002357922.1,WP_002391 204.1，WP_002357417.1，WP_002297874.1，WP_002359573.1, WP_002414999.1, WP_011109458.1, and WP_033072606.1). These results explain that, in our experimental system, dopa/dopamine was readily detected in intestinal bacterial cultures in the presence or absence of BBR. Transplantation of either $E$. faecalis or $E$. faecium into the PGF mice caused the synthesis of dopa/dopamine in the intestinal tract; then, intestinal dopa/dopamine entered the blood, leading to an increase in dopamine in the brain. TMP-TFBderivatized MALDI-MS imaging of dopamine in ICR mouse brains confirmed that the combination of BBR with either $E$. faecalis or $E$. faecium caused a further increase in brain dopamine and ameliorated PD symptoms in the C57 mouse model. The results suggest that the two bacterial strains might be helpful for the brain function through the action of dopa/dopamine production in intestine, and that drug regulation of this process might further improve brain function. 


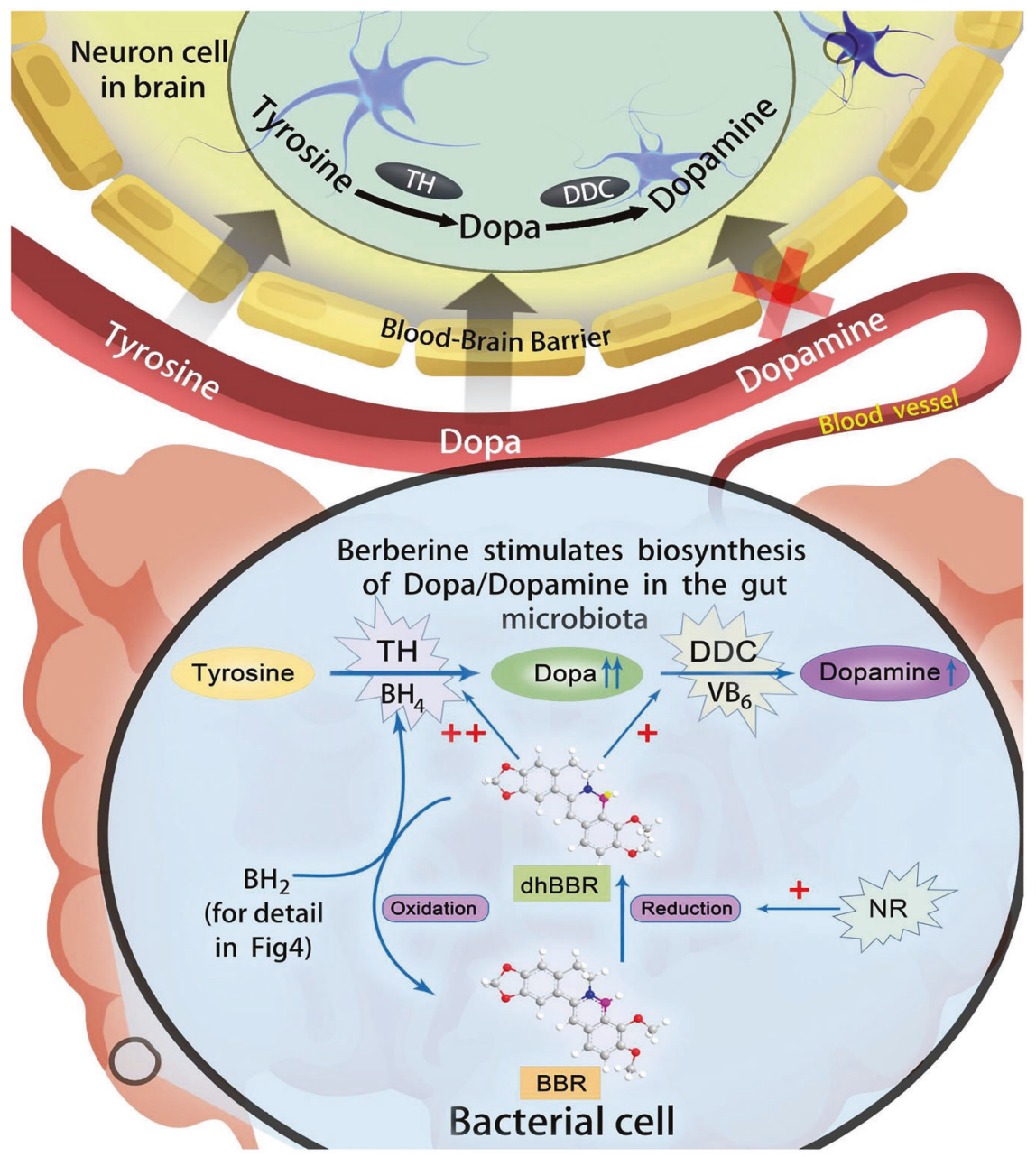

TH: tyrosine hydroxylase; DDC: dopa decarboxylase ; $\mathrm{BH}_{4}$ : tetrahydrobiopterin; NR: nitroreductase; $\mathrm{VB}_{6}$ : vitamin $\mathrm{B}_{6}$

Fig. 7 Dopa/dopamine might be the chemical link for the crosstalk between gut and brain. The regulation of Phe-Tyr-dopa-dopamine biosynthesis in the gut microbiota by BBR could improve brain function

\section{CONCLUSION}

This study discovered first that the gut microbiota is a new source of dopa/dopamine in the body, and second, BBR enhanced TH to produce L-dopa by triggering the biosynthesis of $\mathrm{BH}_{4}$ in the gut microbiota. As BBR has been an OTC drug for many years, it might have immediately applicable potential in regulating gut-brain dialog and improving brain function in humans.

\section{MATERIALS AND METHODS}

\section{Chemicals and reagents}

BBR, dopamine, and L-dopa were obtained from J\&K Scientific Ltd (Beijing, China). 3,4-Dihydroxybenzylamine (as an internal standard, IS) was purchased from Alfa Aesar Chemical Co., Ltd (Ward Hill, MA, USA). Tyrosine, phenylalanine, a-methylphenylalanine, BLMA5 (an inhibitor of TH), and benserazide (an inhibitor of DDC) were obtained from Solarbio Life Science Co., Ltd (Beijing, China). ${ }^{15} \mathrm{~N}$-Tyrosine $\left({ }^{15} \mathrm{~N}\right.$-Tyr, purity $\left.>98 \%\right)$ was obtained from Cambridge Isotope Laboratories, Inc. (MA, USA). Cefadroxil, terramycin, and erythromycin were obtained from Solarbio Life Science Co., Ltd (Beijing, China). Carbidopa was from Selleckchem (Selleck Chemicals, Houston, TX, USA). P and MPTP-HCL were from Medchemexpress (MedChem Express LLC, Princeton, NJ, USA).
The purity of the standards above was $>98 \%$ (HPLC). The TH ELISA kit was from Shanghai Bangyi Biotechnology, Ltd (Shanghai, China). The DDC ELISA kit was from Shuangying Biological, Ltd (Shanghai, China). The PAH ELISA kit and $\mathrm{BH}_{4}$ ELISA kit were obtained from Shanghai Fusheng, Ltd (Shanghai, China) and Shanghai Jianglai, Ltd (Shanghai, China), respectively. The ROS assay kit was from the Nanjing Jiancheng Bioengineering Institute (Nanjing, China).

Animals

ICR mice (male, 18-22 g), Sprague-Dawley (SD) rats (male, 180-200 g), and C57BL mice (male, $22 \pm 3 \mathrm{~g}$ ) were supplied by Vital River Laboratory Animal Technology Co., Ltd (Beijing, China), and they were housed in a controlled environment ( $21 \pm$ $2{ }^{\circ} \mathrm{C}, 12$-h light/dark cycle) with free access to food and water during the acclimatization and study periods in an SPF-grade room. The research was conducted in accordance with the institutional guidelines and ethics, and approved by the Laboratories Institutional Animal Care and Use Committee of the Chinese Academy of Medical Sciences and Peking Union Medical College. The research was conducted in accordance with all guidelines and ethics of the Chinese Council on Animal Care. 
14

\section{Instruments}

A LC/MS ${ }^{n}$-IT-TOF from Shimadzu Corporation (Kyoto, Japan) was used to identify the chemical structures of BBR and its metabolites. LC-MS/MS (8050, Shimadzu Corporation, Kyoto, Japan) was used for the analysis and quantification of dopamine, phenylalanine, tyrosine, and L-dopa. LC separation was achieved using an Alltima $\mathrm{C}_{18}$ column $(5 \mu \times 150 \mathrm{~mm}$, W. R. Grace \& Co, Columbia, USA) maintained at $40^{\circ} \mathrm{C}$. The mobile phase for L-dopa, dopamine, tyrosine, and phenylalanine consisted of water-formic acid (100:0.1, v/v) (A) and acetonitrile (B) with a linear gradient elution (A:B, 0 min, 90:10; 2 min, 90:10; $3 \mathrm{~min}, 5: 95 ; 5 \mathrm{~min}, 5: 95 ; 5.01 \mathrm{~min}, 90: 10 ; 8 \mathrm{~min} 90: 10)$ at a flow rate of $0.8 \mathrm{~mL} / \mathrm{min}$ during the whole gradient cycle. Shimadzu LC-MS solution (Version 5.72) was used for data acquisition and processing. For positive ESI analysis, the parameters were as follows: nebulizer gas, $3 \mathrm{~L} / \mathrm{min}$; drying gas, $10.0 \mathrm{~L} / \mathrm{min}$; interface, $-4.5 \mathrm{kV}$; CID gas, $230 \mathrm{kPa}$; and $\mathrm{DL}$ temperature, heat block temperature were maintained at $200^{\circ} \mathrm{C}$ and $250^{\circ} \mathrm{C}$, respectively. Quantification was carried out using multiple reaction monitoring mode. The $\mathrm{m} / \mathrm{z}$ transitions were $154.20 \rightarrow 91.10(\mathrm{~m} / \mathrm{z})$ for dopamine, $198.15 \rightarrow$ $107.05(\mathrm{~m} / \mathrm{z})$ for L-dopa, $165.85 \rightarrow 120.20(\mathrm{~m} / \mathrm{z})$ for phenylalanine, $182.00 \rightarrow 136.10(\mathrm{~m} / \mathrm{z})$ for tyrosine, and $108.20 \rightarrow 91.10(\mathrm{~m} / \mathrm{z})$ for the IS. The peak areas of those compounds in fluid samples and the IS were recorded, respectively.

Leica CM1950 cryostat microtome (Leica Microsystems, Wetzlar, Germany), rapifleX MALDI-TOF/TOF mass spectrometer (Bruker Daltonik, Bremen, Germany), electrostatic field-assisted matrix automatic sprayer (in-house made), indium tin oxide (ITO) glass slides (Bruker Daltonik, Bremen, Germany), and MTP Slide Adapter II (Bruker Daltonik, Bremen, Germany) were used for TMP-TFBderivatized MALDI-MS imaging of dopamine in ICR mouse brains.

Quantitative analysis of dopa and dopamine in blood, brain, and feces of ICR mice treated with oral BBR by LC-MS/MS

All animals for the experiment were fasted for $12 \mathrm{~h}$ before the test. A total of 60 male ICR mice (19-21 g) were randomly separated into 12 groups $(n=5)$ and BBR was administrated via the oral route. Among them, 20 mice were treated with saline as control, 20 mice were treated with BBR at the dose of $100 \mathrm{mg} / \mathrm{kg}$, and the other 20 mice were treated with BBR at a dose of $200 \mathrm{mg} / \mathrm{kg}$. The samples of blood, brains, and feces were obtained from each group at $0,6,12$, and $24 \mathrm{~h}$ after BBR or saline administration $(n=5)$. With heparin sodium, the blood was centrifuged at $2.4 \times 10^{3} \times g$ for $5 \mathrm{~min}$. Brains were homogenized with normal saline at a ratio of weight $(\mathrm{g}) /$ volume $(\mathrm{mL})(1: 4)$. The IS solution (benzylamine, $0.1 \mu \mathrm{g} / \mathrm{mL}, 10 \mu \mathrm{L}$ ) was added to the blood or brain homogenate $(100 \mu \mathrm{L})$. After precipitating protein with acetonitrile $(300 \mu \mathrm{L})$, samples were mixed for $30 \mathrm{~s}$ and centrifuged at $21.1 \times$ $10^{3} \times g$ for $10 \mathrm{~min}$. An aliquot $(5 \mu \mathrm{L})$ was injected into the LC-MS/ MS 8050 for analysis. Fecal samples $(0.2 \mathrm{~g})$ were extracted with acetonitrile $(900 \mu \mathrm{L})$ by ultrasonication for $5 \mathrm{~min}$, and then the IS solution $(0.1 \mu \mathrm{g} / \mathrm{mL}, 100 \mu \mathrm{L})$ was added. After centrifugation at $21.1 \times 10^{3} \times g$ for $10 \mathrm{~min}$, an aliquot $(5 \mu \mathrm{L})$ was injected into the LC-MS/MS 8050 for analysis. A series of working solutions of dopamine and L-dopa were prepared (at concentrations of 10,000, $1000,100,10,1,0.2$, and $0.1 \mathrm{ng} / \mathrm{mL}$ ) by diluting the stock solution $(1 \mathrm{mg} / \mathrm{mL}$ ) with water. An aliquot of the solutions above $(5 \mu \mathrm{L})$ was injected into the LC-MS/MS 8050 for analysis.

Levels of dopa and dopamine in ICR mice treated with BBR by intraperitoneal administration

BBR (10 and $20 \mathrm{mg} / \mathrm{kg}$ ) was given to 60 male (19-21 g) ICR mice through the i.p. administration route, and 10 mice were injected with the same amount of normal saline as the control. The blood, brains, and feces were obtained at $0,6,12$, and $24 \mathrm{~h}$ post BBR treatment, as described above. The sample processing procedures were also identical to the former methods. Levels of L-dopa and dopamine in the blood, brains, and feces were analyzed by the method described above.
Pseudo-germ-free ICR mice treated with BBR

Forty-six ICR mice (male, 19-21 g) were orally treated with cefadroxil $(100 \mathrm{mg} / \mathrm{kg})$, terramycin $(300 \mathrm{mg} / \mathrm{kg})$, and erythromycin $(300 \mathrm{mg} / \mathrm{kg})$ twice a day for 3 days, and pharmacokinetic examination was performed on the third day after the final administration of antibiotics. The colon contents of six mice were also collected on the third day after the final treatment with antibiotics, and the PGF status was confirmed by culturing fecal samples in the anaerobic incubator on a nutrient agar culture medium. Fecal samples from six nonantibiotic-exposed ICR mice served as control samples. Before oral administration of a single dose of BBR $(200 \mathrm{mg} / \mathrm{kg})$, the other 40 PGF mice were fasted overnight with free access to water. Blood samples were collected from the posterior orbital venous plexus into a heparinized tube at $0,6,12$, and $24 \mathrm{~h}$ post BBR treatment, and then subjected to the procedure described above. Fecal and brain samples were also collected at $0,6,12$, and $24 \mathrm{~h}$ post BBR treatment. The samples were stored at $-20^{\circ} \mathrm{C}$ for further analysis. The blood, brain, and fecal samples processing procedures and analyzing methods for dopa or dopamine are described in the former section.

Determination of ${ }^{15} \mathrm{~N}$-dopamine in brain after injection into the mouse colon with ${ }^{15} \mathrm{~N}$-tyrosine

${ }^{15} \mathrm{~N}$-Tyr (purity $>98 \%$ ) was supplied by Cambridge Isotope Laboratories, Inc. (MA, USA). Thirty-two ICR mice (male, 19-22 g) were randomly divided into three groups: mice treated with ${ }^{15} \mathrm{~N}$-Tyr as group $1(n=8)$, the PGF mice treated with BBR and ${ }^{15} \mathrm{~N}-\mathrm{Tyr}$ as group $2(n=8)$, and mice treated with BBR and ${ }^{15} \mathrm{~N}-\mathrm{Tyr}$ as group $3(n=8)$. The mice in group 2 were given cefadroxil $(100 \mathrm{mg} / \mathrm{kg})$, terramycin (300 mg/kg), and erythromycin (300 mg/kg) twice a day for 3 days, and then BBR $(200 \mathrm{mg} / \mathrm{kg})$ was given orally to the two groups for three successive days. After the above treatment, ${ }^{15} \mathrm{~N}-\mathrm{Tyr}(10 \mathrm{mg} / \mathrm{kg})$ was injected into the colon of anesthetized mice for groups 1-3. After $6 \mathrm{~h}$ of administration, the mice were killed, and the brains were collected for the next analysis.

To estimate the dopamine production by the gut microbiota, 12 ICR mice (male, 19-22 g) were randomly divided into 2 groups: mice treated with ${ }^{15} \mathrm{~N}$-Tyr as group $1(n=6)$, and those treated with antibiotics and ${ }^{15} \mathrm{~N}$-Tyr group as group $2(n=6)$. The mice in group 2 were given cefadroxil $(100 \mathrm{mg} / \mathrm{kg})$, terramycin $(300 \mathrm{mg} /$ $\mathrm{kg})$, and erythromycin $(300 \mathrm{mg} / \mathrm{kg})$ twice a day for 3 days. Then, ${ }^{15} \mathrm{~N}-\mathrm{Tyr}(10 \mathrm{mg} / \mathrm{kg})$ was injected into mice colon under the conditions of anesthesia for both groups. Six hours later, the mice were killed and the brains were collected for analysis.

${ }^{15} \mathrm{~N}$-Dopamine was detected by LC-MS/MS 8050, and $155.20 \rightarrow$ $137.05(\mathrm{~m} / \mathrm{z})$ was chosen as the quantitative ion pair for ${ }^{15} \mathrm{~N}-$ dopamine. The flow speed was set as $0.5 \mathrm{~mL} / \mathrm{min}$, and the other analytical conditions of HPLC-MS/MS were the same as those of dopamine. Multiple mass spectrometer analysis was performed by LC-MS $^{n}$-IT-TOF. The chromatography conditions were the same as those of LC-MS/MS 8050. Both the temperature of the interface and the curved desolvation line were set at $200^{\circ} \mathrm{C}$. The detector voltage was $1.65 \mathrm{kV}$, and the collision energy was set as $50 \%$.

Biotransformation of ${ }^{15} \mathrm{~N}$-tyrosine into ${ }^{15} \mathrm{~N}$-dopamine in vitro Blood, liver homogenate, brain homogenate, and intestinal bacteria were used to evaluate the biotransformation of ${ }^{15} \mathrm{~N}-\mathrm{Tyr}$ into ${ }^{15} \mathrm{~N}$-dopamine in vitro. ${ }^{15} \mathrm{~N}$-Tyr (final concentration $10 \mu \mathrm{g} / \mathrm{mL}$ ) was added to the above incubation system. BBR $(1 \mathrm{mg} / \mathrm{mL}, 10 \mu \mathrm{L})$ was added to the above incubation system, and methanol $(10 \mu \mathrm{L})$ was added to the other group as the control group. After incubating for 2,4 , and $6 \mathrm{~h},{ }^{15} \mathrm{~N}$-dopamine was tested by LC-MS/ MS using the method described above.

Production of dopa and dopamine stimulated by BBR in the intestinal bacteria in vitro

Colon contents from 15 male ICR mice or 6 SD rats were pooled, and the mixture of colon contents $(5 \mathrm{~g})$ was transferred into a flask 
containing normal saline $(100 \mathrm{~mL})$. After mixing thoroughly, the cultures were preincubated under anaerobic conditions with $\mathrm{N}_{2}$ atmosphere at $37^{\circ} \mathrm{C}$ for $60 \mathrm{~min}$. BBR $(10 \mu \mathrm{L})$ at different concentrations was added to the rat intestinal bacteria cultures $(990 \mu \mathrm{L})$, with methanol $(10 \mu \mathrm{L})$ as the negative control. The final concentrations of BBR in the incubation system were 10 and $20 \mu \mathrm{g} / \mathrm{mL}$. The cultures were incubated for $0,6,12$, and $24 \mathrm{~h}$ at $37^{\circ} \mathrm{C}$. After termination of the reaction with acetonitrile $(1 \mathrm{~mL})$, $10 \mu \mathrm{L}$ of IS solution $(100 \mathrm{ng} / \mathrm{mL})$ was added, and then the incubation was mixed for $30 \mathrm{~s}$ and centrifuged at $21.1 \times 10^{3} \times g$ for $10 \mathrm{~min}$. The supernatant $(100 \mu \mathrm{L})$ was transferred into an eppendorf tube and dried under nitrogen flow at $37^{\circ} \mathrm{C}$, and then the residue was reconstituted with $100 \mu \mathrm{L}$ acetonitrile. After centrifugation at $21.1 \times 10^{3} \times g$ for $5 \mathrm{~min}$, the supernatant was filtered with a $0.22 \mu \mathrm{m}$ filter membrane, and then $5 \mu \mathrm{L}$ of the aliquot was injected into the LC-MS/MS 8050 for dopamine and dopa analysis.

Dopa and dopamine in ten single strains of intestinal bacteria treated with BBR in vitro

Ten strains of intestinal bacteria (Acinetobacter baumanii (A. baumannii, 1), Pseudomonas aeruginosa ( $P$. aeruginosa, 2), Staphylococcus aureus (S. aureus, 3) E. faecalis (E. faecalis, 4), E. faecium (E. faecium, 5), E. coli $(E$. coli, 6), P. mirabilis ( $P$. mirabilis, 7), S. epidermidis (S. epidermidis, 8), L. acidophilus (L. acidophilus, 9), and Bifidobacterium breve (B. breve, 10)) were cultured overnight in the appropriate medium. These bacteria were diluted to a final concentration of $3 \times 10^{8} \mathrm{CFU} / \mathrm{mL}$ and incubated with blank solvent (methanol), BBR $(10 \mu \mathrm{g} / \mathrm{mL})$, and BBR $(20 \mu \mathrm{g} / \mathrm{mL})$ for $12 \mathrm{~h}$. Then, the contents of dopa and dopamine were analyzed via LC-MS/MS 8050. The sample processing procedures were the same as above. Four kinds of single intestinal bacteria ( $E$. faecalis, E. faecium, E. coli, and $P$. mirabilis) were selected from the ten kinds of single strains above and incubated with BBR $(10 \mu \mathrm{g} / \mathrm{mL})$ for 6,12 , and $24 \mathrm{~h}$. Then the levels of dopa and dopamine were determined quantitatively by LC-MS/MS 8050 . The sample processing procedures were the same as above.

Enzyme activity test of TH and DDC in the bacterial strains of $E$. faecalis and $E$. faecium

$E$. faecalis and E. faecium were identically cultivated and counted as described above, and then the bacterial protein extract was prepared as previously described. There were three groups of enzymatic activity tests, including the medium control (group 1), the $E$. faecium group (group 2), and the $E$. faecalis group (group 3). Finally, the detection of enzyme activity was performed according to the manufacturer's guidelines of the ELISA kit.

Dopa and dopamine in brain, liver, and small intestine of the ICR mice when incubated with $B B R$ in vitro

After fasting for $12 \mathrm{~h}, 24$ male ICR mice (19-21 g) were sacrificed by cervical dislocation for the collection of brain, liver, and small intestine after rinsing the intestinal contents with saline. Tissue samples were pooled. After weighing, they were homogenized with four volumes $(V(\mu \mathrm{L}) / W(\mathrm{~g}))$ of saline and stored at $-80^{\circ} \mathrm{C}$. Ten microliters of BBR at different concentrations was added to the mouse brain, liver, or small intestine homogenate $(990 \mu \mathrm{L})$, and methanol $(10 \mu \mathrm{L})$ was added as a negative control. The final concentrations of BBR in the incubation system were 10 and $20 \mu \mathrm{g} / \mathrm{mL}$. The systems were incubated for 6,12 , and $24 \mathrm{~h}$ at $37^{\circ} \mathrm{C}$. Aliquots $(100 \mu \mathrm{L})$ were removed and quenched in twice the volume of acetonitrile. After adding $10 \mu \mathrm{L}$ of IS solution $(3,4-$ dihydroxybenzylamine, $100 \mathrm{ng} / \mathrm{mL}$ ), the samples were mixed for $30 \mathrm{~s}$ and centrifuged at $21.1 \times 10^{3} \times g$ for $10 \mathrm{~min}$. The supernatant was filtered through a $0.22-\mu \mathrm{m}$ micropore membrane, and a $5 \mu \mathrm{L}$ aliquot was analyzed by LC-MS/MS 8050 for dopamine or dopa detection. A $1 \mathrm{mg} / \mathrm{mL}$ stock solution of dopamine or L-dopa was prepared by dissolving in methanol and was stored at $4{ }^{\circ} \mathrm{C}$.
Working solutions were prepared by diluting the stock solution with methanol (to a series of concentrations of 1, 2, 10, 100, 1000, and $10,000 \mathrm{ng} / \mathrm{mL}$ of dopamine or L-dopa). A solution containing IS (3,4-dihydroxybenzylamine, $10 \mu \mathrm{g} / \mathrm{mL}$ ) was prepared in methanol. Calibration curve samples were prepared by spiking blank samples (distilled water) with $1 / 100$ volume of the working solutions. For dopamine and dopa detection, the final concentrations were $0.1,0.21 .0,10,100$, and $1000 \mathrm{ng} / \mathrm{mL}$. According to the method mentioned above, twice the volume of acetonitrile and IS solution $(10 \mu \mathrm{L})$ were added to each sample.

Bacterial composition analysis

The fecal samples of ICR mice for the bacterial composition analysis were classified into three groups: group 1 treated with BBR by oral administration $(200 \mathrm{mg} / \mathrm{kg}, 24 \mathrm{~h}, n=3)$, group 2 treated with BBR by i.p. injection $(20 \mathrm{mg} / \mathrm{kg}, 24 \mathrm{~h}, n=3)$, and the untreated control group $(n=3)$ as group 3 . Gut bacterial composition in the ICR mice was analyzed via $16 \mathrm{~S}$ rRNA gene analysis. The $16 \mathrm{~S}$ rRNA genes were amplified using the specific primer for $16 \mathrm{~S} \mathrm{V3-V4:} \mathrm{340F-805R} \mathrm{to} \mathrm{target} \mathrm{the} \mathrm{V3-V4} \mathrm{regions} \mathrm{of}$ $16 \mathrm{~S}$ rRNA. PCR products were mixed in equidensity ratios. Then, a mixture of PCR products was purified with the GeneJET Gel Extraction Kit (QIAGEN, Germany). Sequencing libraries were generated using the NEXTflex Rapid DNA-seq kit for Illumina (New England Biolabs, USA), following the manufacturer's recommendations, and index codes were added. The library quality was assessed on the Qubit 2.0 Fluorometer (Thermo Scientific, USA) and Agilent Bioanalyzer 2100 system (Agilent Technologies, USA). Finally, the library was sequenced on the HiSeq2500 (Illumina, USA) platform, and 250-bp paired-end reads were generated. Sequences were analyzed using the QIIME software package (Quantitative Insights Into Microbial Ecology). First, the reads were filtered by QIIME quality filters. Then, we picked the representative sequences for each OTU (operational taxonomic unit) and used the RDP (ribosomal database project) classifier to annotate taxonomic information for each representative sequence. Sequences with a similarity over $97 \%$ were assigned to the same OTU.

TH and DDC enzyme activity assays in the intestinal bacteria in vitro

There were three groups of enzymatic activity tests of TH and DDC, including the blank control (group 1), the group treated with BBR $(10 \mu \mathrm{g} / \mathrm{mL}$, group 2$)$, and the group treated with BBR $(10 \mu \mathrm{g} / \mathrm{mL})$ and inhibitors (group 3). BLMA5 hydrochloride (an inhibitor of $\mathrm{TH}$ with a final concentration of $100 \mu \mathrm{M}$ ) and benserazide (an inhibitor of DDC with a final concentration of $100 \mu \mathrm{M}$ ) were preincubated with SD rat gut bacterial cultures for $2 \mathrm{~h}$ at $37^{\circ} \mathrm{C}$, while the same amount of methanol was added as the control. Then, BBR was added (with a final concentration of $10 \mu \mathrm{g} / \mathrm{mL}$ ). After $12 \mathrm{~h}$ of incubation, the SD gut bacterial culture $(50 \mathrm{~mL})$ was centrifuged at $6.2 \times 10^{3} \times g$ at $4{ }^{\circ} \mathrm{C}$ (3K15 Refrigerated Centrifuge, Sigma Laborzentrifugen $\mathrm{GmbH}$, Osterode am Harz, Germany) for 10 min to remove the culture medium. Then, the residue was reconstituted with PBS and centrifuged under the same conditions. Next, the residue was dissolved in PBS $(4 \mathrm{~mL})$ to extract the bacterial proteins with an ultrasonic cell disruptor (Scientz-IID Noise Isolating Chamber, Ningbo Scientz Biotechnology Co. LTD, Ningbo, China) with a circle of $8 \mathrm{~s}$ (ultra for $3 \mathrm{~s}$ ), and the extraction period lasted for $2 \mathrm{~h}$. The protein extracts were centrifuged under the same conditions (see above) to remove insoluble substances. Finally, according to the manufacturer's guidelines, the detection of enzyme activity of TH and DDC was performed using the TH ELISA kit (Batch number: JL18430) and DDC ELISA kit (Batch number: JL47021) all obtained from Shanghai Jianglai Industrial Limited By Share Ltd (Shanghai, China). The experiment procedure is described in the User Instruction of the kit. 
In addition, BLMA5 hydrochloride $(100 \mu \mathrm{M})$ and benserazide $(100 \mu \mathrm{M})$ were incubated with SD rat gut bacterial cultures for $12 \mathrm{~h}$ at $37^{\circ} \mathrm{C}$, with the same amount of methanol as control. After $12 \mathrm{~h}$ incubation, the SD gut bacterial culture $(50 \mathrm{~mL})$ was centrifuged at $6.2 \times 10^{3} \times g$ at $4{ }^{\circ} \mathrm{C}$ for $10 \mathrm{~min}$ to remove the culture medium, then the residue was reconstituted in PBS, and centrifuged under the same condition. Next, the residue was dissolved in $4 \mathrm{~mL}$ PBS to extract the bacterial protein with an ultrasonic cell disruptor. Finally, the enzyme detection for TH and DDC was performed, using the TH ELISA kit and DDC ELISA kit.

Benzylhydrazine and BLMA5 inhibit intestinal bacteria in vitro The intestinal contents of three male SD rats (180-200 g) were collected and added to $20 \mathrm{~mL}$ of sterilized anaerobic medium per gram of intestinal contents. After mixing and filtering, the intestinal contents were incubated for $1 \mathrm{~h}$ at $37^{\circ} \mathrm{C}$, and the corresponding concentration of benzylhydrazine was added at final concentrations of 0,50 , and $100 \mu \mathrm{M}$. The samples were incubated for $12 \mathrm{~h}$ at $37^{\circ} \mathrm{C}$ under anaerobic conditions. Each sample was diluted by $10^{3}, 10^{4}$, and $10^{5}$-fold. Then, these samples were coated on nutrient agar plates and cultured at $37^{\circ} \mathrm{C}$ overnight. The colonies were counted and calculated according to the dilution factor. The experimental procedure to test the effect of BLMA5 on inhibiting the growth of the intestinal bacteria in vitro was consistent with the above.

Tests of tetrahydrobiopterin and vitamin $\mathrm{B}_{6}$ Colon contents from six male SD (180-200 g) rats were pooled, and $5 \mathrm{~g}$ of the mixture of colon contents was transferred into a flask containing normal saline $(100 \mathrm{~mL})$. After mixing thoroughly, the cultures were preincubated under anaerobic conditions with $\mathrm{N}_{2}$ atmosphere at $37^{\circ} \mathrm{C}$ for $60 \mathrm{~min}$. BBR $(10 \mu \mathrm{L})$ at different concentrations was added to the rat intestinal bacteria cultures $(990 \mu \mathrm{L})$, with methanol $(10 \mu \mathrm{L})$ as the negative control. The final concentrations of BBR in the incubation system were 10 and $20 \mu \mathrm{g} / \mathrm{mL}$, respectively. The cultures were incubated for 6,12 , and $24 \mathrm{~h}$ at $37^{\circ} \mathrm{C} . \mathrm{BH}_{4}$ and $\mathrm{VB}_{6}$ in the gut bacteria were determined by the $\mathrm{BH}_{4}$ ELISA kit and $\mathrm{VB}_{6}$ ELISA kit, respectively. Both of them were obtained from Shanghai Jianglai Ltd (Shanghai, China).

Effects of TH or DDC inhibitors on the production of dopa/ dopamine in gut bacteria in vitro

BLMA5 hydrochloride (an inhibitor of $\mathrm{TH}$ with a final concentration of $100 \mu \mathrm{M}$ ) and benserazide (an inhibitor of DDC at a final concentration of $100 \mu \mathrm{M}$ ) were preincubated with SD rat gut bacterial cultures for $2 \mathrm{~h}$ at $37^{\circ} \mathrm{C}$, while the same amount of methanol was added as the control. Then, BBR was added (with a final concentration of 10 or $20 \mu \mathrm{g} / \mathrm{mL}$ ). The incubation times were 6 and $12 \mathrm{~h}$. After termination with acetonitrile, the levels of dopa and dopamine in the incubation were analyzed by the method described above.

Dopa/dopamine, $\mathrm{TH} / \mathrm{DDC}$, and $\mathrm{BH}_{4} / \mathrm{VB}_{6}$ in the brain homogenate treated with BBR or dhBBR

After fasting for $12 \mathrm{~h}, 20$ male ICR mice (19-21 g) were sacrificed by cervical dislocation for brain collection. Brain samples were pooled. After weighing, they were homogenized in saline (with $V$ $(\mathrm{mL}) / W(\mathrm{~g})=1: 5)$. Five microliters of BBR or dhBBR at different concentrations was added to the mouse brain homogenate $(495 \mu \mathrm{L})$, with methanol $(5 \mu \mathrm{L})$ as the negative control. The final concentrations of BBR or dhBBR in the incubation system were 10 and $20 \mu \mathrm{g} / \mathrm{mL}$, respectively. The systems were incubated at $37^{\circ} \mathrm{C}$ for $6 \mathrm{~h}$. The determination of dopa and dopamine was the same LC-MS/MS method as described above. DDC, $\mathrm{TH}_{1} \mathrm{BH}_{4}$, and $\mathrm{VB}_{6}$ in the brain homogenate were determined by the corresponding ELISA kits. All of them were obtained from Shanghai Jianglai Ltd (Shanghai, China).
Effects of BBR and dhBBR on dopamine levels in mouse dopamine neurons

After the mouse dopamine neuron cells were cultured to stability (cells purchased from Procell Life Science \& Technology Co., Ltd), trypsin was added for digestion. Then, the cells were counted and plated in 48-well microplates. Next, the cells were incubated in a $5 \% \mathrm{CO}_{2}$ and $37^{\circ} \mathrm{C}$ cell incubator for $24 \mathrm{~h}$, with the addition of BBR or dhBBR (final concentration of $10 \mu \mathrm{g} / \mathrm{mL}$ ) as the treatment group (DMSO as a control). After $6 \mathrm{~h}$ of culture, the cells were removed for disruption, and the LC-MS/MS method was used for detection of dopamine levels (same method as above).

Reduction of $\mathrm{BH}_{2}$ by dhBBR in the presence of dihydrofolate reductase

The purified enzyme reaction system consisted of $25 \mathrm{mM}$ Tris- $\mathrm{HCl}$ $(\mathrm{pH}=7.4), 1 \mathrm{mM} \mathrm{MgCl}, 0.1 \mu / \mathrm{mL}$ recombinant human DHFR (ProSpec-Tany TechnoGene Ltd, Ness-Ziona, Israel), $1 \mathrm{mM}$ dhBBR (in DMSO), and $1 \mathrm{mM} \mathrm{BH}_{2}$ in a final volume of $100 \mu \mathrm{L}$. DMSO was added as a control. The DHFR was preincubated via centrifugation at 850 r.p.m. at $37^{\circ} \mathrm{C}$ for $3 \mathrm{~min}$, and this step was followed by the addition of $\mathrm{NADPH}$. After reacting for $1 \mathrm{~h}$, the mixture was terminated by adding a threefold volume of ice-cold acetonitrile. Then, the mixture was centrifuged at 12,000 r.p.m. for 5 min, and the supernatant was injected for $\mathrm{BH}_{2}$ or $\mathrm{BH}_{4}$ analysis by LC-MS/MS.

Methotrexate, an inhibitor of DHFR, inhibits dopa/dopamine in gut microbiota

Colon contents from three SD rats were pooled and the mixture of colon contents $(5 \mathrm{~g})$ was transferred into a flask containing saline $(100 \mathrm{~mL})$. After thoroughly mixing, the cultures were preincubated under anaerobic conditions with $\mathrm{N}_{2}$ atmosphere at $37^{\circ} \mathrm{C}$ for $60 \mathrm{~min}$. Methotrexate $(10 \mu \mathrm{L})$, an inhibitor of DHFR, ${ }^{78}$ was added to the rat intestinal bacterial cultures $(990 \mu \mathrm{L})$, with methanol $(10 \mu \mathrm{L})$ as the negative control. The final concentrations of methotrexate in the incubation system were $100 \mu \mathrm{M}$. The cultures were incubated at $37^{\circ} \mathrm{C}$ for $12 \mathrm{~h}$. Then the levels of dopa and dopamine were determined quantitatively by LC-MS/MS 8050 .

\section{Parkinson's disease behavior test on C57 mice}

C57BL mice (male, $22 \pm 3 \mathrm{~g}$ ) were housed at five per cage and were randomly divided into five groups ( $n=10$ in each group): the control group ( $P$, i.p., $200 \mathrm{mg} / \mathrm{kg} / \mathrm{d}$ ) as group 1 ; the MPTP/Pinjected group (MPTP, s.c., $20 \mathrm{mg} / \mathrm{kg}$ and P, i.p., $200 \mathrm{mg} / \mathrm{kg} / \mathrm{d}$ ) as group $2 ;{ }^{79}$ the MPTP/P-injected and BBR-treated (orally) group (MPTP, s.c., $20 \mathrm{mg} / \mathrm{kg}$ and P, i.p., $200 \mathrm{mg} / \mathrm{kg} / \mathrm{d}$; BBR, oral, $200 \mathrm{mg} /$ $\mathrm{kg} / \mathrm{d}$ ) as group 3; the MPTP/P-injected and BBR-treated (i.p.) group (MPTP, s.C., $20 \mathrm{mg} / \mathrm{kg}$ and P, i.p., $200 \mathrm{mg} / \mathrm{kg} / \mathrm{d}$; BBR, i.p., $10 \mathrm{mg} / \mathrm{kg} /$ d) group as group 4; and the MPTP/P-injected and L-dopa/ carbidopa-treated group as the positive control (MPTP, s.C., $20 \mathrm{mg} /$ $\mathrm{kg}$ and P, i.p., $200 \mathrm{mg} / \mathrm{kg} / \mathrm{d}$; days 2-7, L-dopa, s.C., $10 \mathrm{mg} / \mathrm{kg} / \mathrm{d}$ and carbidopa, s.C., $1 \mathrm{mg} / \mathrm{kg}$ ) as group 5 . In all the groups, rotarod and vertical pole performance test and CT occurred $1 \mathrm{~h}$ later. The BBR treatment started 5 days prior to MPTP/P treatment and lasted throughout the entire experiment, and all five groups were treated with MPTP/P for 7 days. Rotarod performance was measured on a rotating rod (YLS-4C Rotarod, Yiyan Science and Technology Development Co., Ltd, Jinan, China) as the mice walked forward to avoid falling off a continuously rotating cylinder. Mice were tested at a rotational speed of 15 r.p.m. on MPTP/P-treated days 1 and 7. Three trials were measured, and the average time on the rod for each mouse was used for data analysis. Time on the rod was used to assess fine motor coordination and balance. The vertical pole descent test (YLSQ15 Pole, Yiyan Science and Technology Development Co., Ltd, Jinan, China) was conducted on MPTP/P-treated mice on days 1 and 7. Mice were placed at the top of a coarse, vertical wooden pole in a cage, and allowed to descend. They were first given a 
practice run and then three test trials. The time to reach the cage bottom was recorded. If the mouse did not descend or dropped or slipped down the pole without climbing, a default value of $60 \mathrm{~s}$ was recorded. The descent times of the three tests were averaged. CT was performed in a $1000 \mathrm{~mL}$ beaker, as previously described. ${ }^{80}$ Each mouse was placed in a glass beaker. The mice freely moved in the beaker and the times of ipsilateral/contralateral paw touches were recorded for $10 \mathrm{~min}$ to monitor the physical coordination of each animal. The results were calculated by the ratio of ipsilateral touches to the total of ipsilateral plus contralateral touches. The test was conducted on MPTP/P-treated mice on days 1 and 7. C57 mice were sacrificed immediately to obtain their blood and brains after the behavioral examination. The sample processing procedures were identical to the former part. Dopa and dopamine of the blood, brains, and feces were analyzed by the method mentioned in the former section.

Transplantation of E. faecalis and E. faecium to ICR mice Forty-two ICR mice (male, 18-22 g) were randomly divided into seven groups: the mice treated with PBS as group $1(n=6$, negative control), the mice treated with PBS as group 2 ( $n=6$, PGF control), the mice treated with BBR $(200 \mathrm{mg} / \mathrm{kg} / \mathrm{d}$, oral) as the group 3 , the mice treated with $E$. faecalis $\left(6 \times 10^{8} \mathrm{CFU} / \mathrm{d}\right.$, oral) as group 4 , the mice treated with $E$. faecalis and BBR $(200 \mathrm{mg} / \mathrm{kg} / \mathrm{d}$, oral) as group 5, the mice treated with $E$. faecium $\left(6 \times 10^{8} \mathrm{CFU} / \mathrm{d}\right.$, oral) as group 6 , and the mice treated with E. faecium and BBR as group 7. The mice in groups 2-7 were orally given cefadroxil $(100 \mathrm{mg} / \mathrm{kg})$, terramycin $(300 \mathrm{mg} / \mathrm{kg})$, and erythromycin $(300 \mathrm{mg} / \mathrm{kg})$ twice a day for 3 days, and then BBR $(200 \mathrm{mg} / \mathrm{kg})$ or bacteria were given orally to the five groups for three successive days. The PGF status was confirmed by culturing fecal samples in the anaerobic incubator on nutrient agar culture medium, using the method described above. After transplantation, the brain, blood, and feces were collected for dopa and dopamine detection.

To verify the colonization of transplanted bacteria, the number of $E$. faecium in fecal samples was evaluated by quantitative PCR. Firstly, the total nucleic acid in samples was extracted by the Genomic DNA extraction Kit (Tiangen Biochemical Technology Co., LTD, Beijing, China) according to the instructions. Then, qPCR was performed in a total volume of $50 \mu \mathrm{L}$, which contained $200 \mathrm{nM}$ primers, $1 \mu \mathrm{L}$ of DNA template, $25 \mu \mathrm{L}$ of $2 \times$ Taq MaterMix (TaKaRa), and $22 \mu \mathrm{L}$ of water (TaKaRa). Primers were as following: EF-F, TGCTCCACCGGAAAAAGA (5'-3'); EF-R, CACCAACTAGCTAA TGCA $\left(5^{\prime}-3^{\prime}\right)$. qPCR was performed in the Fluorescence quantitative $P C R$ instrument $(A B I 7500$, Applied Biosystems, Shanghai, China) following the program: $5 \mathrm{~min}$ at $95^{\circ} \mathrm{C}, 30$ cycles of $30 \mathrm{~s}$ at $94^{\circ} \mathrm{C}, 30 \mathrm{~s}$ at $55^{\circ} \mathrm{C}$, and $30 \mathrm{~s}$ at $72^{\circ} \mathrm{C}$, followed by a cycle of $10 \mathrm{~min}$ at $72^{\circ} \mathrm{C}$. The calibration curves of the target gene were obtained from the plasmid with target fragment. And the absolute DNA copies were regarded as the level of $E$. faecium in samples.

Transplantation of $E$. coli to ICR mice

Eighteen ICR mice (male, 18-22 g) were randomly divided into three groups. The mice were treated with PBS as group $1(n=6$, negative control), the PGF mice were treated with PBS as group 2 ( $n=6$, PGF control), and the PGF mice were treated with $E$. coli as group 3 . The mice in groups 2 and 3 were orally given cefadroxil $(100 \mathrm{mg} / \mathrm{kg})$, terramycin $(300 \mathrm{mg} / \mathrm{kg})$, and erythromycin $(300 \mathrm{mg} /$ $\mathrm{kg}$ ) twice a day for 3 days, and the bacterial solution was orally given for three successive days. After transplantation, the brain, blood, and feces were collected for dopa and dopamine detection.

Test of reactive oxygen species

The levels of ROS were measured in five groups, namely, the blank control (group 1), the E. coli group (group 2), the E. faecium group (group 3), the $E$. faecalis group (group 4), and the positive control group ( $E$. coli treated with $\mathrm{H}_{2} \mathrm{O}_{2}$, group 5). After $24 \mathrm{~h}$ of culture of $E$. coli, E. faecalis, and E. faecium, the number of bacteria was calibrated for the kit assay. The detection of ROS in bacteria was then performed according to the manufacturer's guidelines. A ROS assay kit was obtained from Nanjing Jiancheng Bioengineering Institute (Nanjing, China).

2,4,6-Trimethyl-pyranylium tetrafluoroborate-derivatized MALDIMS imaging of dopamine in ICR mouse brain

Eighteen ICR mice (male, 18-22 g) were randomly divided into six groups, namely, groups 1-6. The mice in groups 1 and 2 were treated with $\mathrm{PBS}$, and the mice in group 3 were treated with $E$. faecalis $\left(6 \times 10^{8} \mathrm{CFU} / \mathrm{d}\right.$, orally); the mice in group 4 were treated with $E$. faecalis $\left(6 \times 10^{8} \mathrm{CFU} / \mathrm{d}\right.$, orally) and BBR $(200 \mathrm{mg} / \mathrm{kg} / \mathrm{d}$, orally); the mice in group 5 were treated with $E$. faecium $\left(6 \times 10^{8}\right.$ $\mathrm{CFU} / \mathrm{d}$, orally); the mice in group 6 were treated with $E$. faecium $\left(6 \times 10^{8} \mathrm{CFU} / \mathrm{d}\right.$, orally) and BBR. The mice in groups 2-6 were orally given cefadroxil $(100 \mathrm{mg} / \mathrm{kg})$, terramycin $(300 \mathrm{mg} / \mathrm{kg})$, and erythromycin $(300 \mathrm{mg} / \mathrm{kg})$ twice a day for 3 days, and then BBR or bacteria were orally given to the four groups for three successive days.

The brain tissue was placed on a tin foil container after it was separated and frozen in liquid nitrogen until the tissue turned completely white. Then, the frozen brain tissues were cut using a cryostat microtome (Leica CM1950, Leica Microsystems). The tissue was first kept in the freezing chamber, the temperature of which was $-20^{\circ} \mathrm{C}$ and equilibrated for $2 \mathrm{~h}$. A layer of water was dripped on the sample holder as a frozen embedding solution, and the striatum sections were cut at a thickness of $12 \mu \mathrm{m}$. Tissue sections were transferred with a precooled brush onto conductive ITO glass slides (Bruker). After being dried for $30 \mathrm{~min}$, the samples were stored at $-80^{\circ} \mathrm{C}$ until analysis.

The derivatization method was adopted from a published protocol with slight modification according to the instrument available (Shariatgorji ${ }^{45}$ ). TMP-TFB was dissolved in methanol to prepare $8 \mathrm{mg} / \mathrm{mL}$ stock solutions. Derivatization was performed using solutions containing $120 \mathrm{~mL}$ of the stock solution of TMPTFB in $6 \mathrm{~mL}$ of $70 \%$ methanol buffered by $3.5 \mu \mathrm{L}$ of triethylamine. The derivatization reagent was sprayed over the tissue with a flow rate of $40 \mathrm{~L} / \mathrm{min}$. The nozzle temperature of the sprayer was kept at $80^{\circ} \mathrm{C}$. The treated tissue samples were then incubated for $30 \mathrm{~min}$ (dried by nitrogen flow every $10 \mathrm{~min}$ ) in a chamber saturated with $50 \%$ methanol solution.

a-Cyano-4-hydroxy-cinnamic acid (CHCA) was used as the assisted matrix. CHCA $(10 \mathrm{mg} / \mathrm{mL})$ was prepared in a $50 \%$ methanol solution containing $0.1 \%$ trifluoroacetic acid. The MALDI-MS matrix was applied to the tissue using the same inhouse automatic sprayer. The nozzle temperature was set at $95^{\circ} \mathrm{C}$ with a flow rate of $20 \mathrm{~L} / \mathrm{min}$. MALDI-MS imaging experiments were performed using a rapifleX MALDI-TOF/TOF mass spectrometer (Bruker). The coated tissue slice was placed in the mass spectrometer. After TeachMaker calibration, the pixel size of the imaging resolution was defined for optimal acquisition performance. MS imaging data were visualized using Flexlmaging (Bruker). After the data were normalized by total ion current, the neurotransmitter peak was determined, and the mass spectrum peak after derivatization was $444.1985 \pm 0.02$ to evaluate the distribution of dopamine in the tissue area. The peak height was selected to represent the relative abundance of biomolecules. The colored spots in the image represent the location of the compound, and the color of each spot is related to the intensity of the signal detected by the laser at each point or pixel.

Parkinson's disease behavior test on C57 mice treated with $E$. faecalis and E. faecium

C57BL mice (male, $22 \pm 3 \mathrm{~g}$ ) were housed at four to five per cage and were randomly divided into seven groups $(n=10-13$ in each group): the control group (P, i.p., $200 \mathrm{mg} / \mathrm{kg} / \mathrm{d}$ ) as group 1; the MPTP/P-injected group (MPTP, s.C., $20 \mathrm{mg} / \mathrm{kg}$ and P, i.p., $200 \mathrm{mg} /$ 
$\mathrm{kg} / \mathrm{d}$ ) as group 2; the MPTP/P-injected and BBR-treated (orally) group (MPTP, s.C., $20 \mathrm{mg} / \mathrm{kg}$ and P, i.p., $200 \mathrm{mg} / \mathrm{kg} / \mathrm{d}$; BBR, orally, $200 \mathrm{mg} / \mathrm{kg} / \mathrm{d}$ ) as group 3; the MPTP/P-injected and E. faeciumtreated (orally) group (MPTP, s.C., $20 \mathrm{mg} / \mathrm{kg}$ and P, i.p., $200 \mathrm{mg} / \mathrm{kg} /$ $\mathrm{d}$; E. faecium, orally, $6 \times 10^{8} \mathrm{CFU} / \mathrm{d}$ ) group as group 4; the MPTP/Pinjected and $E$. faecalis-treated (orally) group (MPTP, s.C., $20 \mathrm{mg} / \mathrm{kg}$ and P, i.p., $200 \mathrm{mg} / \mathrm{kg} / \mathrm{d}$; E. faecalis, orally, $6 \times 10^{8} \mathrm{CFU} / \mathrm{d}$ ) as group 5; the MPTP/P-injected and E. faecium and BBR-treated (orally) group (MPTP, s.C., $20 \mathrm{mg} / \mathrm{kg}$ and P, i.p., $200 \mathrm{mg} / \mathrm{kg} / \mathrm{d}$; E. faecium, orally, $6 \times 10^{8} \mathrm{CFU} / \mathrm{d}$; BBR, orally, $200 \mathrm{mg} / \mathrm{kg} / \mathrm{d}$ ) group as group 6; and the MPTP/P-injected and E. faecalis and BBR-treated (orally) group (MPTP, s.C., $20 \mathrm{mg} / \mathrm{kg}$ and P, i.p., $200 \mathrm{mg} / \mathrm{kg} / \mathrm{d}$; E. faecalis, orally, $6 \times 10^{8}$ CFU/d; BBR, orally, $200 \mathrm{mg} / \mathrm{kg} / \mathrm{d}$ ) as group 7 . In all the groups, the rotarod and vertical pole performance were tested $1 \mathrm{~h}$ later. The treatment of BBR, E. faecium, or E. faecalis started 5 days prior to MPTP/P treatment and lasted throughout the entire experiment, and all seven groups were treated with MPTP/P for 7 days. The tests of rotarod performance and vertical pole descent were performed as previously described on days 3,5 , and 7 . Three trials were measured, and the average time for each mouse was used for data analysis. All C57 mice were sacrificed immediately to obtain their blood and brains after behavioral examination. The sample processing procedures were also identical to the former part. The levels of dopa/dopamine in blood, brains, and feces were analyzed by the method mentioned in the previous section.

\section{Clinical trials}

Twenty-eight patients (17 males, 11 females; age $65.2 \pm 7.0$ ) with high levels of blood lipids/glucose (blood cholesterol $(\mathrm{mmol} / \mathrm{L})$, $5.56 \pm 1.03$; triglyceride $(\mathrm{mmol} / \mathrm{L}), 3.17 \pm 4.10 ; \mathrm{LDL}-\mathrm{C}(\mathrm{mmol} / \mathrm{L})$, $3.10 \pm 0.81$; and FBG $(\mathrm{mmol} / \mathrm{L}), 6.76 \pm 2.65)$ were enrolled in the study in the Outpatient Section of the First Hospital of Jilin University in Changchun in the summer of 2017. The study was approved by the institutional ethics committee of the hospital (ChiCTR-OPN17012942), and all the patients provided informed consent. Seven of them had both high blood lipids and glucose. The subjects were not undergoing any drug treatment before enrollment. Before BBR treatment, blood samples were taken from each individual as the control; 5-gram fecal samples from the 28 individuals were collected for enzyme activity tests (TH and DDC) immediately.

The 28 patients were orally treated with BBR $(0.5$ grams, bid) for 2 months. Blood samples were collected in the morning on the first day 2 months later and placed at $-20^{\circ} \mathrm{C}$. Before the last treatment (within $24 \mathrm{~h}$ ), 5-gram fecal samples from the 28 individuals were collected, and immediately prepared for measurement of the enzyme activity of TH and DDC. The fecal samples of BBR treatment were also used for the bacterial composition analysis and calculation of the relative abundance of Enterococcaceae.

The concentrations of dopa and dopamine in plasma and feces of the patients (before/after BBR treatment) were measured using LC-MS/MS as described.

\section{Statistical analysis}

The statistical analyses were conducted using two-way ANOVA and Student's $t$ test with GraphPad Prism Version 5 (GraphPad Software, CA, USA). The data are expressed as the means \pm standard deviation. $P$ values $<0.05$ were considered statistically significant.

\section{DATA AVAILABILITY}

The data used and/or analyzed to support the findings of this study are available in this paper or the Supplementary Information. Any other raw data that support the findings of this study are available from the corresponding author upon reasonable request.

\section{ACKNOWLEDGEMENTS}

The work was supported by CAMS Innovation Fund for Medical Sciences (CIFMS; No. 2016-I2M-3-011), the National Natural Science Foundation of China (Nos. 81573493 and 81973290), Beijing Key Laboratory of Non-Clinical Drug Metabolism and PK/PD study (Z141102004414062), the Key Project of Beijing Natural Science Foundation (No.7181007), National Mega-project for Innovative Drugs and the National Megaproject for Innovative Drugs (No. 2018ZX09711001-002-002). The authors thank Shimadzu (China) Co., Ltd for the technological supports in the analysis of metabolites, as well as Guidon Pharmaceutics for the technological service in MS imaging experiment.

\section{AUTHOR CONTRIBUTIONS}

J.D.-J., X.T.C. and Y.W. conceived of and designed the experiments and contributed to the writing and editing of the manuscript. Z.-X.Z., S.-R.M., J.-W.S., X.-Y.L., X.-F.Z., T.-L.G., B.-Y.W., L.-B.P., L.C., R.P., Y.L., J.-B.Y., H.Y., and J.F. performed the experiments. J.D.-J. and Y.W. analyzed the data. J.D.-J., Y.W., and Q.T. contributed to discussions and provided reagents/materials/analysis tools important for completion of the work.

\section{ADDITIONAL INFORMATION}

The online version of this article (https://doi.org/10.1038/s41392-020-00456-5) contains supplementary material, which is available to authorized users.

Competing interests: The authors declare no competing interests.

Ethics declarations: The clinical trial was performed in accordance with the Declaration of Helsinki and has been approved by the institutional ethics committee of the First Hospital of Jilin University with the registration number of ChiCTR-OPN17012942 (on Chinese Clinical Trial Registry). Informed consents were obtained from all the subjects. All the animal studies have been approved by the Laboratories Institutional Animal Care and Use Committee of the Chinese Academy of Medical Sciences and Peking Union Medical College. The research was conducted in accordance with all guidelines and ethics of both institutional guidelines and the Chinese Council on Animal Care.

\section{REFERENCES}

1. O'Toole, P. W. \& Jeffery, I. B. Gut microbiota and aging. Science 350, 1214-1215 (2015).

2. Sampson, T. R. et al. Gut microbiota regulate motor deficits and neuroinflammation in a model of Parkinson's disease. Cell 167, 1469-1480 (2016).

3. Perry, R. J. et al. Acetate mediates a microbiome-brain- $\beta$-cell axis to promote metabolic syndrome. Nature 534, 213-217 (2016).

4. Kim, S. et al. Maternal gut bacteria promote neurodevelopmental abnormalities in mouse offspring. Nature 549, 528-532 (2017).

5. Sharon, G., Sampson, T. R., Geschwind, D. H. \& Mazmanian, S. K. The central nervous system and the gut microbiome. Cell 167, 915-932 (2016).

6. Zhang, Z., Tang, H., Chen, P., Xie, H. \& Tao, Y. G. Demystifying the manipulation of host immunity metabolism, and extraintestinal tumors by the gut microbiome. Sig. Transduct. Target Ther. 4, 41 (2019).

7. Seeman, P. in The Dopamine Receptors, Historical Overview: Introduction to the Dopamine Receptors (ed Neve K.) 1-22 (Humana Press, Totowa, 2010).

8. Broadley, K. J. The vascular effects of trace amines and amphetamines. Pharmacol. Ther. 125, 363-375 (2010).

9. Lindemann, L. \& Hoener, M. C. A renaissance in trace amines inspired by a novel GPCR family. Trends Pharmacol. Sci. 26, 274-281 (2005).

10. Møller, N., Meek, S., Bigelow, M., Andrews, J. \& Nair, K. S. The kidney is an important site for in vivo phenylalanine-to-tyrosine conversion in adult humans: A metabolic role of the kidney. Proc. Natl Acad. Sci. USA 97, 1242-1246 (2000).

11. Cumming, P. \& Gjedde, A. Compartmental analysis of dopa decarboxylation in living brain from dynamic positron emission tomograms. Synapse 29, 37-61 (1998).

12. Blau, N., van Spronsen, F. J. \& Levy, H. L. Phenylketonuria. Lancet 376, 1417-1427 (2010).

13. Connolly, B. S. \& Lang, A. E. Pharmacological treatment of Parkinson disease: a review. JAMA 311, 1670-1683 (2014).

14. Nagatsu, T., Nakashima, A., Ichinose, H. \& Kobayashi, K. Human tyrosine hydroxylase in Parkinson's disease and in related disorders. J. Neural Transm. 126, 397-409 (2019).

15. Kim, H. L. \& Park, Y. S. Maintenance of cellular tetrahydrobiopterin homeostasis. BMB Rep. 43, 584-592 (2010).

16. Belik, J. et al. Intestinal microbiota as a tetrahydrobiopterin exogenous source in hph-1 mice. Sci. Rep. 7, 39854 (2017). 
17. Iyer, L. M., Aravind, L., Coon, S. L., Klein, D. C. \& Koonin, E. V. Evolution of cell-cell signaling in animals: did late horizontal gene transfer from bacteria have a role? Trends Genet. 20, 292-299 (2004).

18. Rekdal, V. M., Bess, E. N., Bisanz, J. E., Turnbaugh, P. J. \& Balskus, E. P. Discovery and inhibition of an interspecies gut bacterial pathway for Levodopa metabolism. Science 364, eaau6323 (2019).

19. O'Neill, C. Gut microbes metabolize Parkinson's disease drug. Science 364, 1030-1031 (2019).

20. Kurt, A. G., Aytan, E., Ozer, U., Ates, B. \& Geckil, H. Production of L-DOPA and dopamine in recombinant bacteria bearing the Vitreoscilla hemoglobin gene. Biotechnol. J. 4, 1077-1088 (2009).

21. Divyashri, G., Krishna, G. \& Prapulla, S. G. Probiotic attributes, antioxidant, antiinflammatory and neuromodulatory effects of Enterococcus faecium CFR 3003: in vitro and in vivo evidence. J. Med. Microbiol. 64, 1527-1540 (2015)

22. Yano, J. M. et al. Indigenous bacteria from the gut microbiota regulate host serotonin biosynthesis. Cell 161, 264-276 (2015).

23. Kong, W. et al. Berberine is a novel cholesterol-lowering drug working through a unique mechanism distinct from statins. Nat. Med. 10, 1344-1351 (2004).

24. Derosa, G. et al. Effects of berberine on lipid profile in subjects with low cardiovascular risk. Expert. Opin. Biol. Ther. 13, 475-482 (2013).

25. Lee, Y. S. et al. Berberine, a natural plant product, activates AMP-activated protein kinase with beneficial metabolic effects in diabetic and insulin-resistant states. Diabetes 55, 2256-2264 (2006).

26. Kong, W. J. et al. Berberine reduces insulin resistance through protein kinase Cdependent up-regulation of insulin receptor expression. Metabolism 58, 109-119 (2009).

27. Durairajan, S. S. et al. Berberine ameliorates-amyloid pathology, gliosis, and cognitive impairment in an Alzheimer's disease transgenic mouse model. Neurobiol. Aging 33, 2903-2919 (2012).

28. Patil, S., Tawari, S., Mundhada, D. \& Nadeem, S. Protective effect of berberine, an isoquinoline alkaloid ameliorates ethanol-induced oxidative stress and memory dysfunction in rats. Pharmacol. Biochem. Behav. 136, 13-20 (2015).

29. Kim, M. et al. Berberine prevents nigrostriatal dopaminergic neuronal loss and suppresses hippocampal apoptosis in mice with Parkinson's disease. Int. J. Mol. Med. 33, 870-878 (2014)

30. Kwon, I. H. et al. Effects of berberine on 6-hydroxydopamine-induced neurotoxicity in PC12 cells and a rat model of Parkinson's disease. Neurosci. Lett. 486 29-33 (2010).

31. Tan, X. S. et al. Tissue distribution of berberine and its metabolites after oral administration in rats. PloS ONE 8, e77969 (2013).

32. Liu, Y. T. et al. Extensive intestinal first-pass elimination and predominant hepatic distribution of berberine explain its low plasma levels in rats. Drug Metab. Dispos. 38, 1779-1784 (2010)

33. Feng, R. et al. Transforming berberine into its intestine-absorbable form by the gut microbiota. Sci. Rep. 5, 12155 (2015)

34. Cotzias, G. C., Papavasiliou, P. S. \& Gellene, R. Modification of parkinsonismchronic treatment with L-dopa. N. Engl. J. Med. 280, 337-345 (1969).

35. Tate, S. S., Sweet, R., McDowell, F. H. \& Meister, A. Decrease of the 3, 4dihydroxyphenylalanine (DOPA) decarboxylase activities in human erythrocytes and mouse tissues after administration of DOPA. Proc. Natl Acad. Sci. USA 68 2121-2123 (1971).

36. Lyte, M. Induction of gram-negative bacterial growth by neurochemical containing banana (Musa x paradisiaca) extracts. FEMS Microbiol. Lett. 154, 245-250 (1997).

37. Koyanagi, T. et al. Eukaryotic-type aromatic amino acid decarboxylase from the root colonizer Pseudomonas putida is highly specific for 3, 4-dihydroxyphenyl-Lalanine, an allelochemical in the rhizosphere. Microbiology 158, 2965-2974 (2012).

38. Liu, W. H. et al. Alteration of behavior and monoamine levels attributable to Lactobacillus plantarum PS128 in germ-free mice. Behav. Brain. Res. 298, 202-209 (2016).

39. Dairman, W., Christenson, J. G. \& Udenfriend, S. Changes in tyrosine hydroxylase and dopa decarboxylase induced by pharmacological agents. Pharmacol. Rev. 24, 269-289 (1972).

40. Pavon, J. A., Eser, B., Huynh, M. T. \& Fitzpatrick, P. F. Single turnover kinetics of tryptophan hydroxylase: evidence for a new intermediate in the reaction of the aromatic amino acid hydroxylases. Biochemistry 49, 7563-7571 (2010).

41. Guibal, P. et al. Simultaneous determination of all forms of biopterin and neopterin in cerebrospinal fluid. ACS Chem. Neurosci. 5, 533-541 (2014).

42. Lo, A. et al. Single-step rapid diagnosis of dopamine and serotonin metabolism disorders. ACS Omega 2, 5962-5972 (2017).

43. Beal, M. F. Experimental models of Parkinson's disease. Nat. Rev. Neurosci. 2 325-334 (2001).

44. Raghuraman, G., Rai, V., Peng, Y. J., Prabhakar, N. R. \& Kumar, G. K. Pattern-specific sustained activation of tyrosine hydroxylase by intermittent hypoxia: role of reactive oxygen species-dependent downregulation of protein phosphatase $2 \mathrm{~A}$ and upregulation of protein kinases. Antioxid. Redox Signal. 11, 1777-1789 (2009).
45. Shariatgorji, M. et al. Direct targeted quantitative molecular imaging of neurotransmitters in brain tissue sections. Neuron 84, 697-707 (2014).

46. Hu, X. C., Wan, J. W. \& Hu, R. J. Analysis of clinical distribution characteristics and drug tolerance of Enterococci in Wuxi between 2008-2009. Journal of Modern. Lab. Med. 6, 125-127 (2010).

47. Wang, Y. et al. Gut microbiota-mediated personalized treatment of hyperlipidemia using berberine. Theranostics 7, 2443-2451 (2017).

48. Yao, J., Kong, W. J. \& Jiang, J. D. Learning from berberine: treating chronic diseases through multiple targets. Sci. China Life Sci. 58, 854-859 (2015).

49. Wang, Y. et al. Berberine-induced bioactive metabolites of the gut microbiota improve energy metabolism. Metabolism 70, 72-84 (2017).

50. Ishikawa, T. et al. Genetic and pharmacological correction of aberrant dopamine synthesis using patient iPSCs with BH4 metabolism disorders. Hum. Mol. Genet. 25, 5188-5197 (2016)

51. Elsas, L. J., Greto, J. \& Wierenga, A. The effect of blood phenylalanine concentration on Kuvan ${ }^{\mathrm{TM}}$ response in phenylketonuria. Mol. Genet. Metab. 102, 407-412 (2011)

52. Fonteh, A. N. et al. Identification of disease markers in human cerebrospinal fluid using lipidomic and proteomic methods. Dis. Markers 22, 39-64 (2006).

53. Hu, G., Jousilahti, P., Bidel, S., Antikainen, R. \& Tuomilehto, J. Type 2 diabetes and the risk of Parkinson's disease. Diabetes Care 30, 842-847 (2007).

54. Bohnen, N. I. et al. Diabetes mellitus is independently associated with more severe cognitive impairment in Parkinson disease. Parkinsonism. Relat. Disord. 20, 1394-1398 (2014).

55. Petrov, D. et al. High-fat diet-induced deregulation of hippocampal insulin signaling and mitochondrial homeostasis deficiences contribute to Alzheimer disease pathology in rodents. Biochim. Biophys. Acta 1852, 1687-1699 (2015).

56. Forsythe, P. \& Bienenstock, J. Gut microbiota: microbiota and behaviour: visiting the sins of the mother. Nat. Rev. Gastroenterol. Hepatol. 13, 502-504 (2016).

57. Yamamoto, S. \& Seto, E. S. Dopamine dynamics and signaling in Drosophila: an overview of genes, drugs and behavioral paradigms. Exp. Anim. 63, 107-119 (2014).

58. Hall, $H$. et al. Distribution of $D_{1}$ - and $D_{2}$-dopamine receptors, and dopamine and its metabolites in the human brain. Neuropsychopharmacology 11, 245-256 (1994).

59. Ashby, F. G., Valentin, V. V. \& von Meer, S. S. Differential effects of dopaminedirected treatments on cognition. Neuropsychiatr. Dis. Treat. 11, 1859-1875 (2015).

60. Besson, C. \& Louilot, A. Asymmetrical involvement of mesolimbic dopaminergic neurons in affective perception. Neuroscience 68, 963-968 (1995).

61. Kalalian-Moghaddam, H., Baluchnejadmojarad, T., Roghani, M., Goshadrou, F. \& Ronaghi, A. Hippocampal synaptic plasticity restoration and anti-apoptotic effect underlie berberine improvement of learning and memory in streptozotocindiabetic rats. Eur. J. Pharmacol. 698, 259-266 (2013).

62. De Deurwaerdère, $P$., Di Giovanni, G. \& Millan, M. J. Expanding the repertoire of LDOPA's actions: a comprehensive review of its functional neurochemistry. Prog. Neurobiol. 151, 57-100 (2017).

63. Cedarbaum, J. M., Kutt, H., Dhar, A. K., Watkins, S. \& Mc Dowell, F. H. Effect of supplemental carbidopa on bioavailability of I-dopa. Neurology 35, 711 (1985).

64. Halkias, I. A., Haq, I., Huang, Z. \& Fernandez, H. H. When should levodopa therapy be initiated in patients with Parkinson's disease? Drug. Aging 24, 261-273 (2007).

65. Calabresi, P., Ghiglieri, V., Mazzocchetti, P., Corbelli, I. \& Picconi, B. Levodopainduced plasticity: a double-edged sword in Parkinson's disease? Philos. Trans. $R$. Soc. B 370, 1672 (2015).

66. Chowdhury, R. et al. Dopamine restores reward prediction errors in old age. Nat. Neurosci. 16, 648-653 (2013).

67. Cenci, M. A. Presynaptic mechanisms of L-DOPA-induced dyskinesia: the findings, the debate, and the therapeutic implications. Front. Neurol. 5, 242 (2014).

68. Mansour, N. M. et al. Isolation of Enterococcus faecium NM113, Enterococcus faecium NM213 and Lactobacillus casei NM512 as novel probiotics with immunomodulatory properties. Microbiol. Immunol. 58, 559-569 (2014).

69. Nami, Y. et al. A newly isolated probiotic Enterococcus faecalis strain from vagina microbiota enhances apoptosis of human cancer cells. J. Appl. Microbiol. 117, 498-508 (2014).

70. Abdhul, K. et al. Antioxidant activity of exopolysaccharide from probiotic strain Enterococcus faecium (BDU7) from Ngari. Int. J. Biol. Macromol. 70, 450-454 (2014).

71. Chai, W. et al. Antiviral effects of a probiotic Enterococcus faecium strain against transmissible gastroenteritis coronavirus. Arch. Virol. 158, 799-807 (2013).

72. Molina, M. A. et al. Immunostimulatory effects triggered by Enterococcus faecalis CECT7121 probiotic strain involve activation of dendritic cells and interferongamma production. PloS ONE 10, e0127262 (2015).

73. Nueno-Palop, C. \& Narbad, A. Probiotic assessment of Enterococcus faecalis, CP58 isolated from human gut. Int. J. Food Microbiol. 145, 390-394 (2011).

74. Wang, S., Hibberd, M. L., Pettersson, S. \& Lee, Y. K. Enterococcus faecalis from healthy infants modulates inflammation through MAPK signaling pathways. PloS ONE 9, e97523 (2014)

75. Surwase, S. N. \& Jadhav, J. P. Bioconversion of L-tyrosine to L-DOPA by a novel bacterium Bacillus sp. JPJ. Amino Acids 41, 495-506 (2011). 
76. Houck, D. R., Hanners, J. L., Unkefer, C. J., van Kleef, M. A. \& Duine, J. A. PQQ: biosynthetic studies in Methylobacterium AM1 and Hyphomicrobium X using specific 13 C labeling and NMR. Antonie Van Leeuwenhoek 56, 93-101 (1989).

77. Muñoz, A. J. et al. Metabolic engineering of Escherichia coli for improving L-3, 4dihydroxyphenylalanine (L-DOPA) synthesis from glucose. J. Ind. Microbiol. Biot. 38, 1845 (2011).

78. Tian, H. \& Cronstein, B. N. Understanding the mechanisms of action of methotrexate. Bull. NYU Hosp. Jt Dis. 65, 168-173 (2007).

79. Ayton, S., Lei, P., Mclean, C., Bush, A. I. \& Finkelstein, D. I. Transferrin protects against Parkinsonian neurotoxicity and is deficient in Parkinson's substantia nigra. Sig. Transduct. Target Ther. 1, 16015 (2016).

80. Zhou, H. et al. Glia-to-neuron conversion by CRISPR-CasRx alleviates symptoms of neurological disease in mice. Cell 181, 590-603 (2020).
Open Access This article is licensed under a Creative Commons Attribution 4.0 International License, which permits use, sharing, adaptation, distribution and reproduction in any medium or format, as long as you give appropriate credit to the original author(s) and the source, provide a link to the Creative Commons license, and indicate if changes were made. The images or other third party material in this article are included in the article's Creative Commons license, unless indicated otherwise in a credit line to the material. If material is not included in the article's Creative Commons license and your intended use is not permitted by statutory regulation or exceeds the permitted use, you will need to obtain permission directly from the copyright holder. To view a copy of this license, visit http://creativecommons.org/licenses/by/4.0/.

(c) The Author(s) 2021 